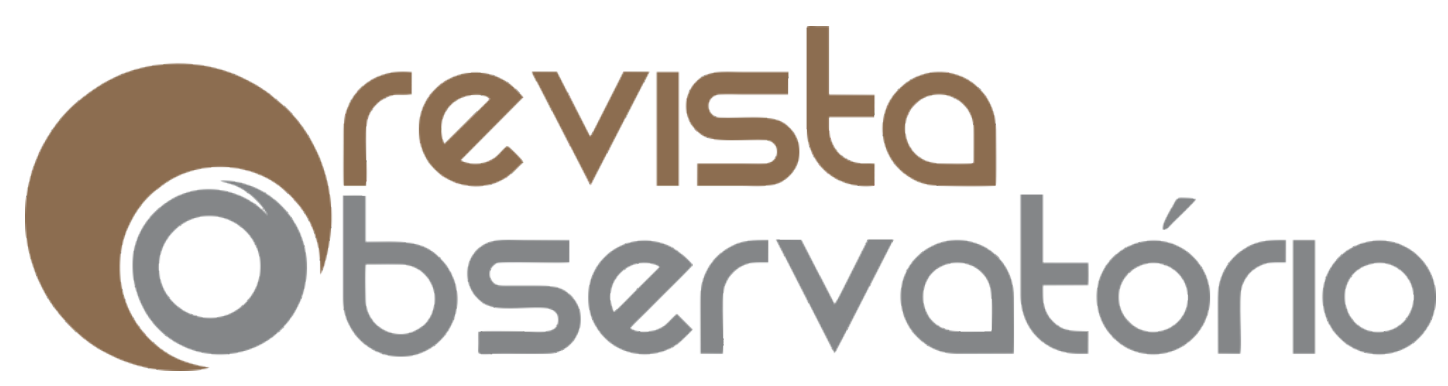

ISSN n² 2447-4266

Vol. 5, n. 5, Agosto. 2019

DOI: http://dx.doi.org/10.20873/uft.2447-4266.2019v5n5p426

\section{PESQUISA DE SATISFAÇÃO COM ACADÊMICOS DO CURSO DE TECNOLOGIA EM LOGÍSTICA EM RELAÇÃO AOS PROFESSORES E INFRAESTRUTURA DO CAMPUS}

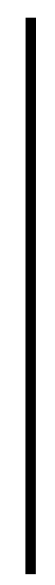

RESEARCH OF SATISFACTION WITH ACADEMICS OF THE LOGISTICS TECHNOLOGY COURSE IN RELATION TO THE TEACHERS AND CAMPUS INFRASTRUCTURE

INVESTIGACIÓN DE SATISFACCIÓN CON ACADÉMICOS DEL CURSO DE TECNOLOGÍA

EN LOGÍSTICA EN RELACIÓN A LOS PROFESORES E INFRAESTRUCTURA DEL CAMPUS

\author{
Kleber Abreu Sousa ${ }^{1}$ \\ Elizabeth Aparecida Corrêa Menezes ${ }^{2}$ \\ Kelly Cristina Dos Santos Lima ${ }^{3}$
}

\title{
RESUMO
}

Conhecer a expectativa do acadêmico em relação a sua instituição de ensino é fundamental para a edificar uma educação superior sólida. $O$ presente artigo avaliou o nível de satisfação dos acadêmicos do curso de Tecnologia em Logística da Universidade Federal do Tocantins; e também, busca analisar elementos ligados a satisfação dos discentes quanto à organização institucional, o corpo docente e a infraestrutura física. Quanto à natureza da pesquisa, este trabalho recorreu à pesquisa de campo e bibliográfica, em forma quali-quantitativa.

\footnotetext{
${ }^{1}$ Pos Doutor em Desenvolvimento Regional pela UNIOESTE. Doutor em Gestão da Inovação pela UFAM. Mestre em Engenharia de Produção pela UFAM. Graduado em Administração de Empresas. Professor Adjunto da Universidade Federal do Tocantins. E-mail: kleberabreu@uft.edu.br.

2 Doutora em Administração de Empresas pela Mackenzi. Mestre em Administração de Empresas pela UNB. Graduada em Administração. Atualmente é professora adjunta da Universidade Federal do Tocantins. E-mail: elisabeth@uft.edu.br.

${ }^{3}$ Graduada em tecnología em Logística pela Universidade Federal do Tocantins. E-mail: kellcris@uft.edu.br.
} 


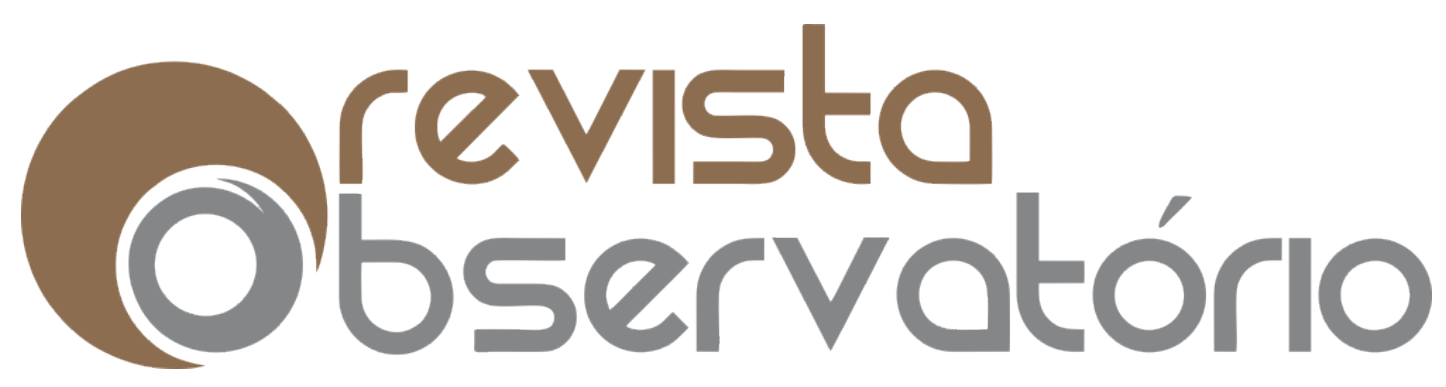

ISSN n² 2447-4266

Vol. 5, n. 5, Agosto. 2019

DOI: http://dx.doi.org/10.20873/uft.2447-4266.2019v5n5p426

Quanto aos resultados desse estudo foi comprovado que os acadêmicos demonstraram satisfação.

PALAVRAS-CHAVE: Acadêmicos; Satisfação; Ensino.

\begin{abstract}
Knowing the expectation of logic in relation to your institution of education is fundamental for a continuous higher education. The present article evaluated the level of academic satisfaction of the Logistics Technology course at the Federal University of Tocantins; and also the search for elements aimed at students' satisfaction regarding the institutional organization, the faculty and the physical infrastructure. About the research, this work is a field research and bibliographical, in qualitative-quantitative form. As for the results of the study it was proved that the students showed satisfaction.
\end{abstract}

KEYWORDS: Academics; Satisfaction; Teaching

\title{
RESUMEN
}

Conocer la expectativa del b lógico en relación a su institución de enseñanza es fundamental para una educación superior continua. El presente artículo evaluó el nivel de satisfacción de los académicos del curso de Tecnología en Logística de la Universidad Federal de Tocantins; $y$, también, la búsqueda de elementos orientados hacia la satisfacción de los discentes en cuanto a la organización institucional, el cuerpo docente y la infraestructura física. Sobre la investigación, este trabajo es una investigación de campo y bibliográfica, en forma cualcuantitativa. En cuanto a los resultados del estudio se comprobó que los académicos demostraron satisfacción.

PALABRAS CLAVE: académicos; la satisfacción; Educación.

Recebido em: 29.04.2019. Aceito em: 12.06.2019. Publicado em: 01.08.2019. 


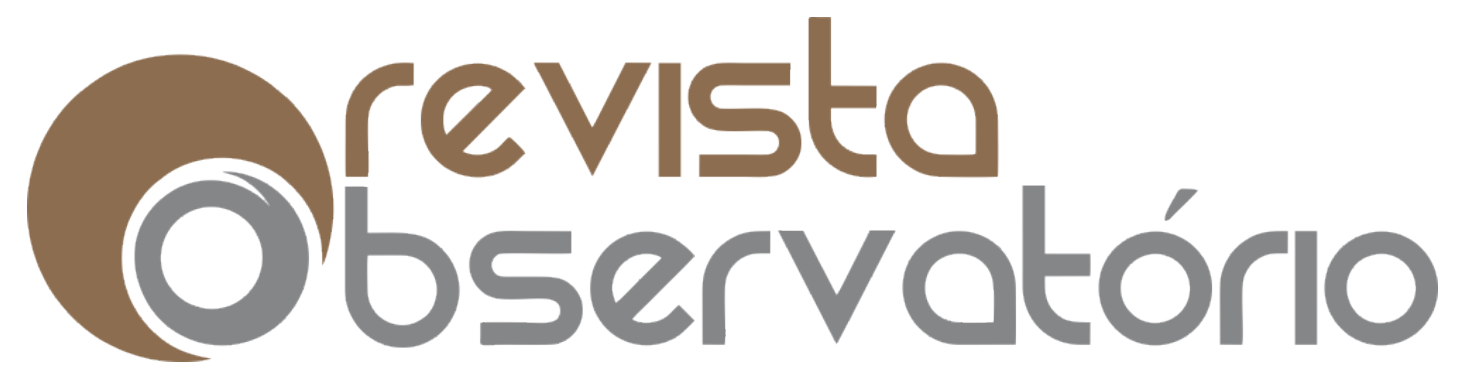

ISSN n² 2447-4266

Vol. 5, n. 5, Agosto. 2019

DOI: http://dx.doi.org/10.20873/uft.2447-4266.2019v5n5p426

\section{Introdução}

A pesquisa de satisfação é um instrumento de grande relevância para a construção de uma educação de excelência, a atividade de ensinar e aprender vai além de transmitir conceitos ultrapassados, ou de repassar saber. Portanto, identificar e gerar melhorias da imagem e do nível de satisfação constituem preocupações constantes das Instituições de Ensino Superior - IES empenhadas em se manter competitivas no mercado.

Assim, as IES devem identificar as necessidades atuais e futuras da sociedade, ou da região onde estão localizadas, devendo estar atentas às mudanças, avaliando permanentemente os currículos, disciplinas e formas de ensino, com o processo de melhoria contínua em parte da cultura organizacional. Esta preocupação é também do MEC (Ministério da Educação e Cultura) que promulgou a Lei $\mathrm{n}^{\circ}$ 10.861, de 14 de abril de 2004, o Sistema Nacional de Avaliação da Educação Superior (Sinaes), que é formado por três componentes principais: a avaliação das instituições; dos cursos; e do desempenho dos estudantes.

O Sinaes avalia todos os aspectos em torno dos três eixos: o ensino, a pesquisa, a extensão; a responsabilidade social; o desempenho dos alunos; a gestão da instituição; o corpo docente; as instalações e vários outros aspectos. Tendo como um de seus objetivos melhorar a qualidade da educação superior e orientar a expansão da oferta, o Sinaes propõe uma avaliação das IES integrada por diversos instrumentos complementares: a auto avaliação da instituição; a avaliação externa; o ENADE (Exame Nacional de Desempenho dos Estudantes) e as condições de ensino e instrumentos de informação, censo e cadastro.

Tendo em vista todo o arcabouço de variáveis para serem analisadas no que se refere à satisfação dos alunos nas instituições de nível superior, neste caso instituição pública, este estudo, por meio de uma pesquisa de campo, procura 


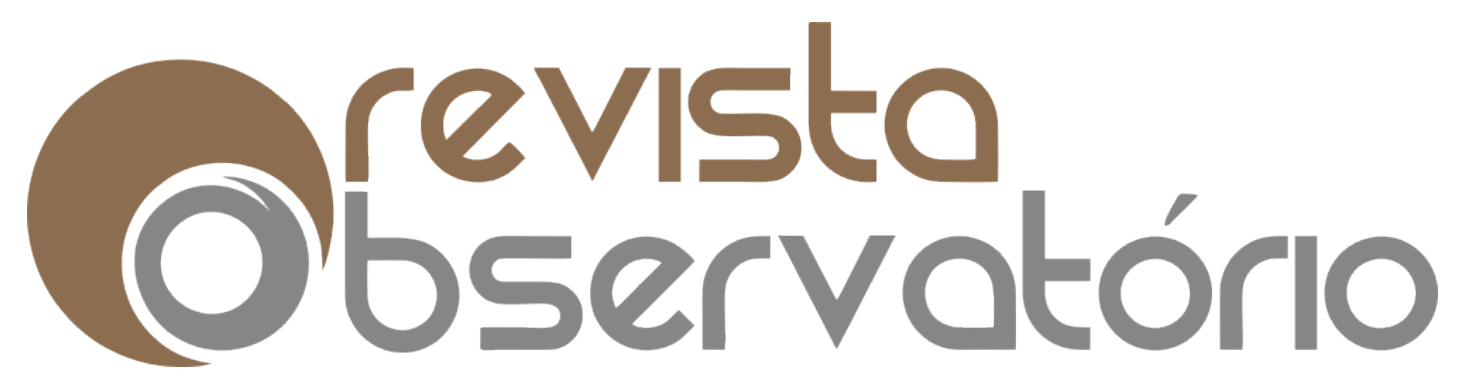

ISSN n² 2447-4266

Vol. 5, n. 5, Agosto. 2019

DOI: http://dx.doi.org/10.20873/uft.2447-4266.2019v5n5p426

analisar qual o grau de satisfação dos acadêmicos do curso de tecnologia em logística, levando em consideração as seguintes variáveis: qualidade das disciplinas; relacionamento do professor com o aluno; e a infraestrutura ofertada.

\section{Fundamentação Teórica}

Nos próximos tópicos serão descritos os eixos fundamentais que darão base e sustentação teórica para a realização das reflexões da pesquisa.

\subsection{O Ensino de Nível Superior}

$\mathrm{O}$ ensino superior cresce a largos passos. No passado era voltado à transmissão do saber e a ações sociais, atualmente destina-se à produção de bem intelectual. Essa mudança acontece tanto na área pedagógica, quanto na área administrativa e estrutura física. De acordo com Neves e Ramos (2001 apud Carmo; Silva; Miranda, 2011, p. 2), no cenário atual, as instituições de ensino superior devem preocupar-se com a manutenção de elevados níveis de satisfação frente aos seus alunos, para tanto, não podem limitar-se a ser simples fornecedoras de conhecimento, necessitando estar atentas para uma contínua adaptação das suas estruturas às transformações ocorridas no ambiente. Dessa forma, não basta apenas transmitir o conteúdo predeterminado para o curso, é importante que esteja adaptado à realidade dos alunos e que o mesmo seja constantemente atualizado.

A sobrevivência e a continuidade do sucesso das IES dependem do nível de satisfação dos discentes em relação aos serviços prestados a eles, tanto no âmbito público como privado. Segundo Kotler e Armstrong (2003), um serviço é uma tarefa ou um benefício que uma parte pode oferecer a outra, que é necessariamente intangível e que não permite na propriedade de nenhum bem. Sua produção pode ou não estar vinculada a um produto físico. 


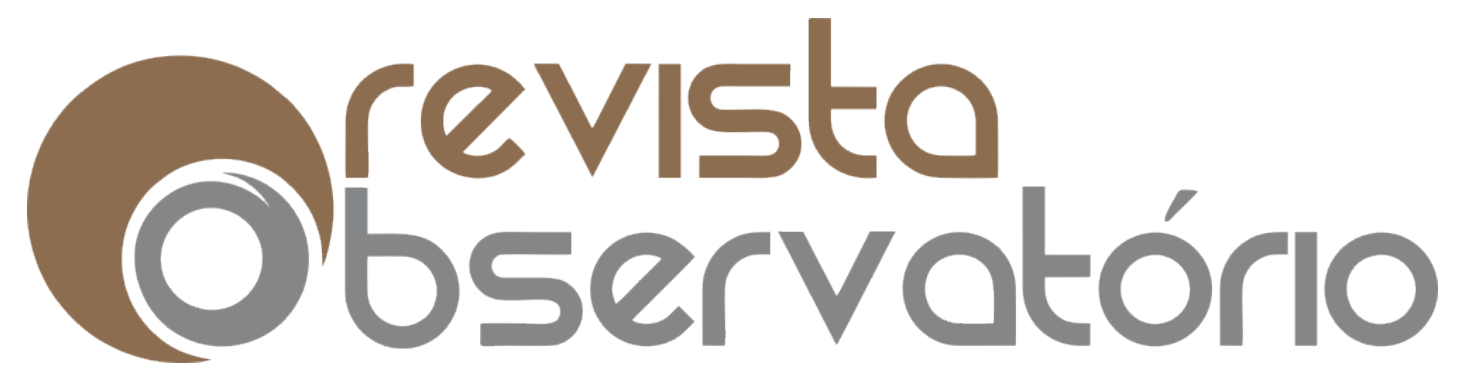

ISSN n² 2447-4266

Vol. 5, n. 5, Agosto. 2019

DOI: http://dx.doi.org/10.20873/uft.2447-4266.2019v5n5p426

Já para Las Casas (2010, p. 284), "os serviços podem ser considerados como atos, ações e desempenho, o que pode mudar é apenas o grau de prestação de serviço que vem incluso. Cada serviço prestado é único e resultará na satisfação ou não do cliente e consequentemente a permanência ou não da empresa no mercado".

De acordo com Kotler (1998, p. 459), existem quatro características importantes nos serviços: a) Intangibilidade: não podem ser vistos, provados, sentidos, ouvidos antes de serem comprados; b) Inseparabilidade: São produzidos e consumidos simultaneamente; c) Variabilidade: são altamente variáveis, já que dependem de quem os executa e de onde são prestados; d) Perecibilidade: refere-se à impossibilidade dos serviços serem estocados.

Quanto a satisfação e o padrão de ensino é necessária a colaboração de todos os envolvidos neste processo. Conforme Rolim (2007) é notório que os alunos detêm responsabilidade sobre a qualidade de sua formação, assim como o desenvolvimento das habilidades exigidas para a prática da profissão, no entanto, as IES partilham das mesmas responsabilidades, devendo caprichar e garantir seu cumprimento.

Quanto à construção do profissional segundo Dencker (2002), as universidades devem formar indivíduos para integrá-los ao mercado de trabalho, harmonizando-o com o sistema de produção. Portanto, proporcionar uma formação adequada, beneficia tanto o profissional, quanto a instituição em que atua, bem como o sistema econômico e social em que este estará inserido.

\section{A Importância da Pesquisa de Satisfação}

No mundo globalizado, a satisfação do cliente e/ou consumidor vem sendo apontada como fator decisivo para o sucesso em diferentes tipos de 


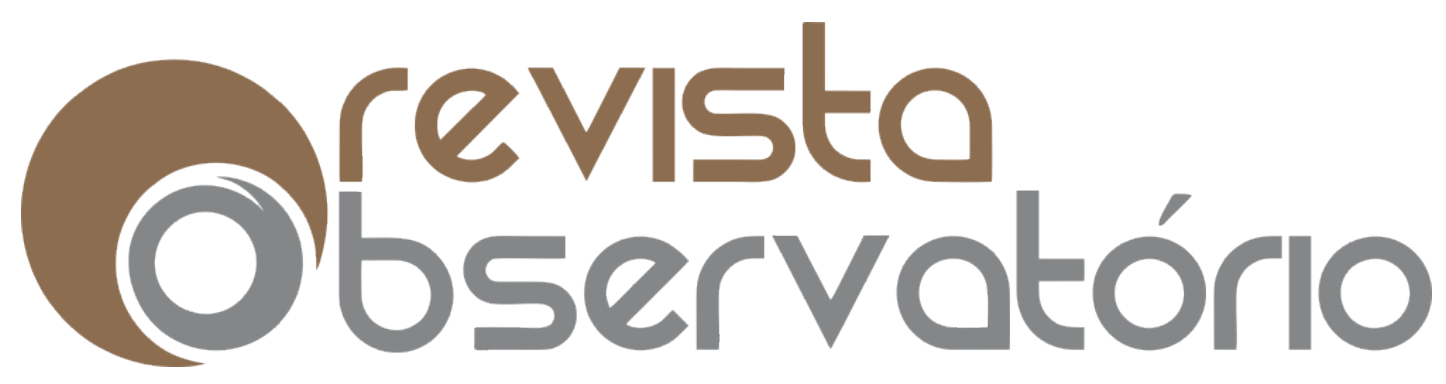

ISSN n² 2447-4266

Vol. 5, n. 5, Agosto. 2019

DOI: http://dx.doi.org/10.20873/uft.2447-4266.2019v5n5p426

organizações. Por isso, a pesquisa de satisfação é uma ferramenta de grande importância. Por meio dela, os dados coletados sobre os níveis de satisfação são conhecidos, analisadas e interpretadas. Fazendo com que os resultados sirvam de estímulo para a adoção de um comportamento comprometido com a qualidade dos serviços oferecidos e, por conseguinte, com os resultados alcançados posteriormente. Pela pesquisa na IES é possível mensurar o que os alunos estão pensando, sentido e o quanto estão aprovando os serviços da universidade. A pesquisa serve para conhecê-los, saber as opiniões e sugestões, bem como para identificar oportunidades de melhorias.

Para a realização de pesquisas de satisfação, é estabelecido um fluxo de informações entre a administração superior e as unidades acadêmicas, que constituirá subsídios extremamente relevantes para o aperfeiçoamento do processo de ensino-aprendizagem e da cultura avaliativa e administrativa da Instituição pesquisada.

Os resultados da avaliação também podem ser usados para a gestão administrativa das unidades acadêmicas, como suporte na elaboração de ajuste curricular, na implementação de novos projetos pedagógicos, na melhoria das condições da estrutura física, no planejamento orçamentário e na elaboração de planos de trabalho capazes de corrigir as dificuldades detectadas no processo de avaliação (UFAM, 2011, pg.23).

Observar e avaliar os processos da organização é extremamente importante, devendo sempre visar à melhoria da qualidade, assim consequentemente atingir a meta principal que é a satisfação total do cliente e/ou consumidor. Desse modo, torna-se necessária a procura da satisfação do discente no ensino superior por meio da qualidade nos serviços prestados. As IES que zelam pela satisfação dos discentes constituem uma parcela predominante 


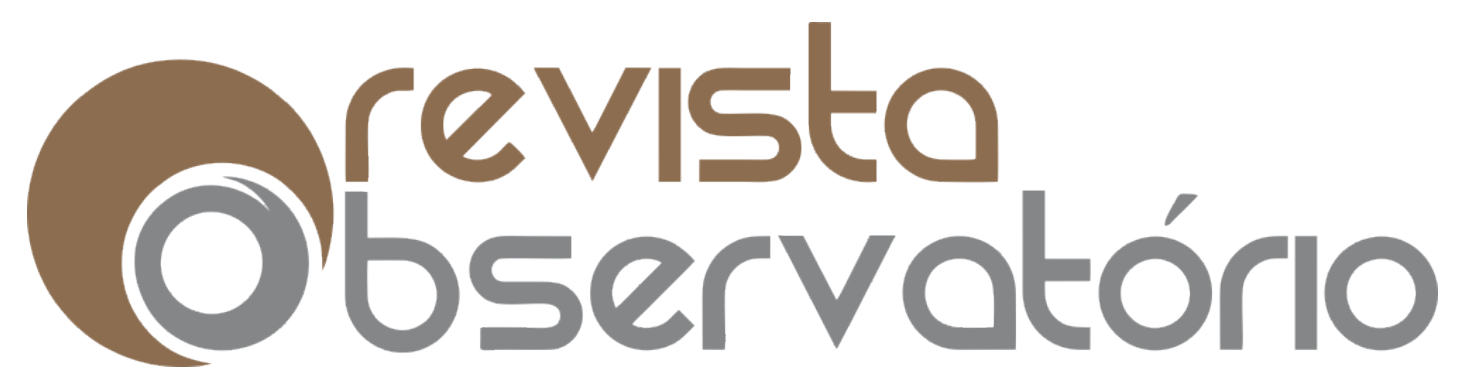

ISSN n² 2447-4266

Vol. 5, n. 5, Agosto. 2019

DOI: http://dx.doi.org/10.20873/uft.2447-4266.2019v5n5p426

do mercado, mostrando-se comprometidas com a qualidade de serviços e com os resultados alcançados junto aos mesmos.

"As universidades atuavam, há alguns anos, de forma passiva nas questões educacionais, principalmente nas relações com o mercado. Porém, atualmente, elas são forçadas a tornarem-se proativas nas suas ações estratégicas, principalmente na identificação e satisfação das expectativas e necessidades de um mercado cada vez mais seletivo e exigente" (LEMKE, 2005, p. 19).

Todos procuram ter um ambiente de trabalho agradável, em que se sintam bem em trabalhar, sintam-se motivados, para exercer melhor suas funções. Toda instituição sempre almeja ser melhor e para isso é imprescindível saber o que o seu cliente e usuários de seus serviços pensam e o que eles desejam para que possa então ir de encontro a isso e realizar ações de melhorias.

\section{Tipos de Escala de uma Pesquisa}

O levantamento de dados para pesquisa quantitativa por meio de questionários requer cuidado especial. Deve-se considerar que não basta apenas coletar respostas sobre questões de interesse, mas sim saber como analisá-las estatisticamente para validação dos resultados. Existem diversas aplicações para a pesquisa de satisfação, são questões simples, porém que mostram muitas vezes informações que nunca foram consideradas importantes, mas que fazem toda a diferença.

A escolha de uma escala está relacionada com a maneira como o entrevistado as interpretará. Ao responder a pessoa processa mentalmente às informações e estas podem estar sujeitas a influências que comprometem a validade das medidas que serão utilizadas. Dentre elas estão às seguintes: 


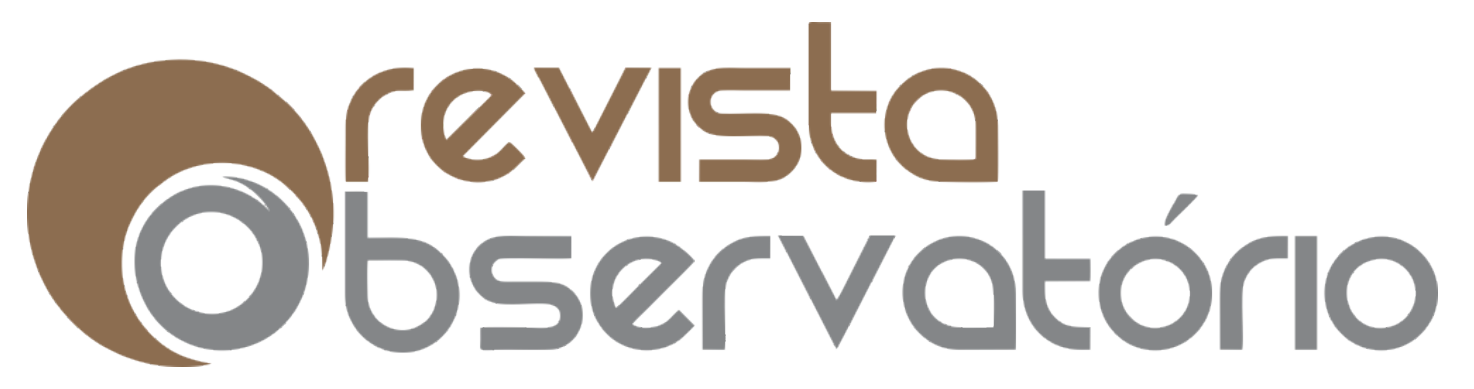

ISSN n² 2447-4266

Vol. 5, n. 5, Agosto. 2019

DOI: http://dx.doi.org/10.20873/uft.2447-4266.2019v5n5p426

Escalas tipo Likert é uma escala composta por um conjunto de afirmações ou itens em relação a cada uma das quais se pede ao entrevistado que avalie para manifestar o grau de concordância desde o discordo totalmente até ao concordo totalmente. A partir das respostas obtidas é somando, calculando a média, do nível selecionado para cada item. Dessa maneira a escala é dada pela média das respostas. Valores acima de 4(quatro) indicam muita satisfação e valores abaixo de 3(três) indicam pouco ou nenhuma satisfação.

Outro tipo de escala é a de Guttman onde é elaborado uma lista de frases relativas a um único tema, muito limitada e repetitiva. Onde a partir das respostas dadas é determinada uma amostra e utilizando um gráfico procede-se à eliminação de itens que não poderão ser ordenados onde apresentam 1 (um) à direita de 0 (zero) ou que se revelam dependentes uns dos outros e estabelecese a ordem de apresentação dos itens que foram selecionados. As frases serão então ordenadas da mais negativa até à mais positiva, onde, a concordância com uma delas, leva tendencialmente à concordância com todas as anteriores.

Já na escala tipo Thurstone que é constituída por um conjunto de frases em relação às quais o sujeito avalia devendo manifestar o seu acordo ou desacordo. Mede-se a atitude do sujeito fazendo a média ponderada dos itens em que houve acordo. Os fatores são calculados na fase de construção da escala.

\section{Formas de Análise de Dados de uma Pesquisa}

Depois de determinado qual escala será utilizada para coleta dos dados da pesquisa é escolhido à forma como estas informações serão tratadas. São muitas as formas de análise de dados que se propõem a realizar este tipo de estudo, estando entre elas, à medida de satisfação simples, a análise de gaps, o 


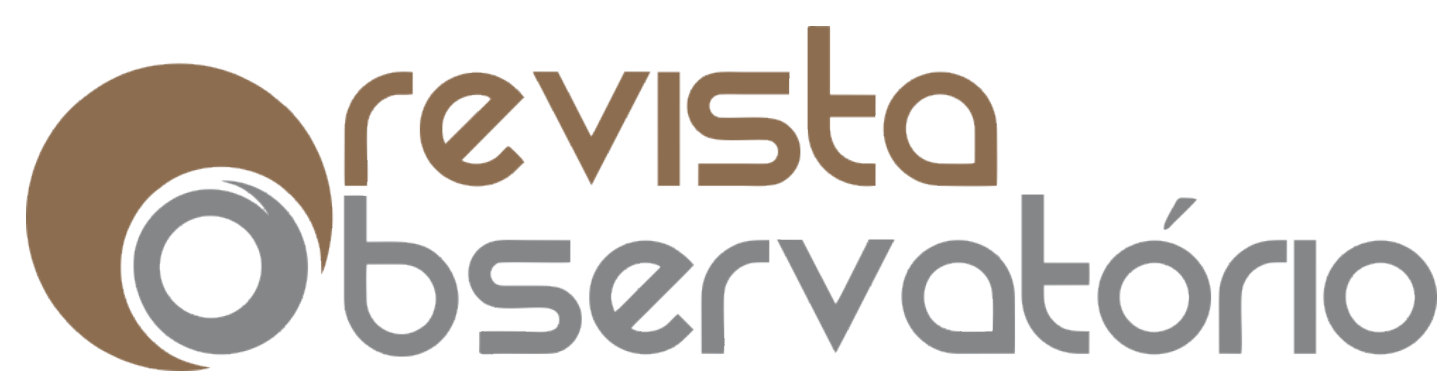

ISSN n² 2447-4266

Vol. 5, n. 5, Agosto. 2019

DOI: http://dx.doi.org/10.20873/uft.2447-4266.2019v5n5p426

modelo I/S (Importância/Satisfação), Survey e a abordagem multiplicativa. (FONTENOT; HENKE; CARSON, 2005, pag. 42).

\begin{tabular}{|c|c|}
\hline FORMA & DESCRIÇÃO \\
\hline Satisfação Simples & $\begin{array}{l}\text { O entrevistado demonstra sua satisfação com } \\
\text { os atributos utilizando uma escala que } \\
\text { indicam se ele está muito satisfeito ou não } \\
\text { está nada satisfeito com o item. As médias são } \\
\text { calculadas, e aqueles com maiores índices } \\
\text { devem ser priorizados. }\end{array}$ \\
\hline Analise de Gaps & $\begin{array}{l}\text { A análise de gaps leva em consideração, } \\
\text { também, a importância dos atributos na } \\
\text { análise. A importância é obtida por meio de } \\
\text { uma escala de diferencial significativo, na qual } \\
\text { um lado significa que o item é muito } \\
\text { importante, e do outro extremo indica que o } \\
\text { item não é nada importante. Assim, a } \\
\text { importância é considerada como medida para } \\
\text { indicar a expectativa de do cliente com cada } \\
\text { atributo, examina a oposição entre a } \\
\text { importância e a satisfação. }\end{array}$ \\
\hline Modelo Importância Satisfação & $\begin{array}{l}\text { O modelo I/S considera a satisfação com o } \\
\text { atributo e a importância afirmada pelos } \\
\text { entrevistados simultaneamente. O método } \\
\text { consiste em utilizar os dados de satisfação e } \\
\text { importância declarada em um gráfico com } 4 \\
\text { quadrantes para se identificar as melhorias } \\
\text { pela comparação do índice de satisfação e a } \\
\text { importância dos atributos. }\end{array}$ \\
\hline
\end{tabular}




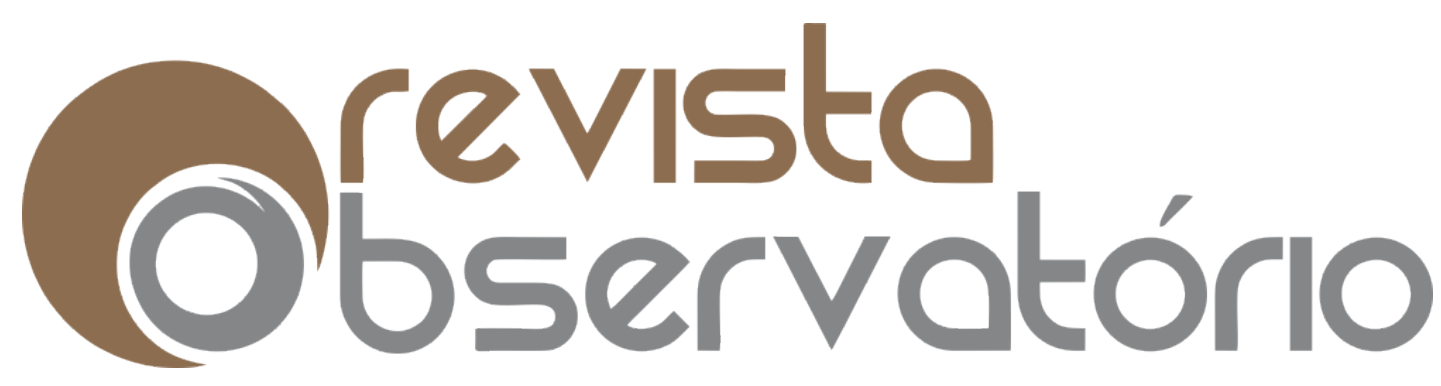

ISSN n² 2447-4266

Vol. 5, n. 5, Agosto. 2019

DOI: http://dx.doi.org/10.20873/uft.2447-4266.2019v5n5p426

\begin{tabular}{|c|l|}
\hline Survey & $\begin{array}{l}\text { Esta técnica se baseia em uma entrevista onde } \\
\text { se utiliza questionários com perguntas } \\
\text { fechadas para se obter informações } \\
\text { padronizadas passíveis de serem tratadas } \\
\text { estatisticamente. Constitui-se em uma das } \\
\text { técnicas de investigação mais utilizadas } \\
\text { atualmente nas pesquisas de satisfação, } \\
\text { devido a sua capacidade de fornecer } \\
\text { informações sobre as percepções e opiniões } \\
\text { dos públicos alvos. }\end{array}$ \\
\hline Abordagem Multiplicativa & $\begin{array}{l}\text { A abordagem multiplicativa usa a importância } \\
\text { como peso para os atributos e elimina a ideia } \\
\text { de identificador da expectativa do cliente. A } \\
\text { diferença entre o índice mais alto possível de } \\
\text { satisfação (totalmente satisfeito) e a } \\
\text { percepção do consumidor sobre a o produto } \\
\text { é utilizada para obter um índice de } \\
\text { insatisfação. }\end{array}$ \\
\hline
\end{tabular}

Quadro 1 - Forma e descrição da análise de dados

Fonte: Elaboração própria.

\section{Avaliação da Qualidade no Ensino}

No processo de ensino e aprendizagem, existe uma série de aspectos que contribuem de formas interdependentes que são de grande importância para alcançar o objetivo proposto almejando sempre o sucesso. Os eixos observados por este estudo levam em consideração: a didática utilizada, o relacionamento existente entre professores e alunos e a infraestrutura do ambiente. 


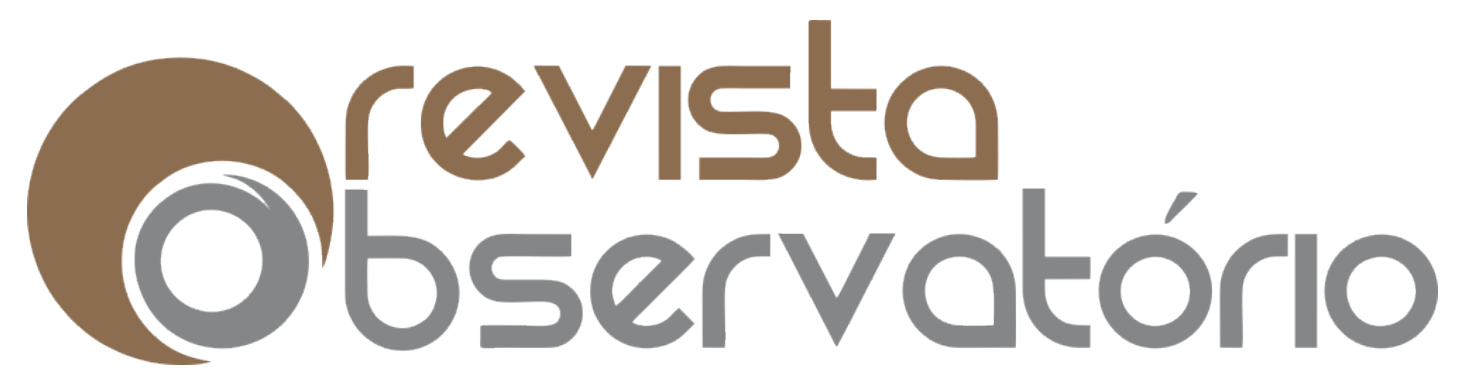

ISSN n² 2447-4266

Vol. 5, n. 5, Agosto. 2019

DOI: http://dx.doi.org/10.20873/uft.2447-4266.2019v5n5p426

De acordo com Moreira (2000) o processo de ensino aprendizagem é constituído de quatro unidades: o professor; o aluno; o conteúdo; e as características variáveis. Cada instituição de ensino, cada um deles podendo manter uma influência de maior ou menor potencial de acordo com o contexto e assim, pode-se detectar as principais influências no processo de ensino: professor - dimensão de relacionamento; aspectos intelectuais e técnicos didáticos; capacidade de ensinar e comprometimento; aluno - capacidade de aprendizagem; experiências e conhecimentos anteriores; interesse; disposição e boa vontade; conteúdo - adequação, significado, aplicação na pratica; instituição - sistema da essência do processo de educação. A compreensão desses atores e da relação entre eles e que deve ser o centro do processo de melhoria da qualidade das IES.

A didática é uma disciplina teórico-prática que pretende subsidiar o professor em todos os elementos constitutivos da dinâmica escolar, quais sejam: a reflexão pedagógica necessária à implementação de um projeto educativo, com suas concepções explicitadas através de seus planejamentos e efetivadas através de sua dinâmica cotidiana. (MELO; URBANETZ, 2008, p. 152).

Já a relação professor e aluno é uma das principais preocupações do contexto educacional. É a interação entre o professor e o aluno que conduz o processo educativo. De acordo como essa interação acontece, a aprendizagem do aluno pode ser mais facilitada ou dificultada, cabe a ambas as partes determinarem o clima dessa relação. Sendo indispensável à importância de estabelecer uma reflexão ao levar em consideração o ambiente escolar como a instituição que tem a possibilidade de construir o conhecimento, é necessária então a criação de possibilidades e condições favoráveis, em que alunos e professores possam refletir sobre as práticas utilizadas e possam construir um ambiente harmonioso que trará mais vantagens para ambas as partes e dessa 


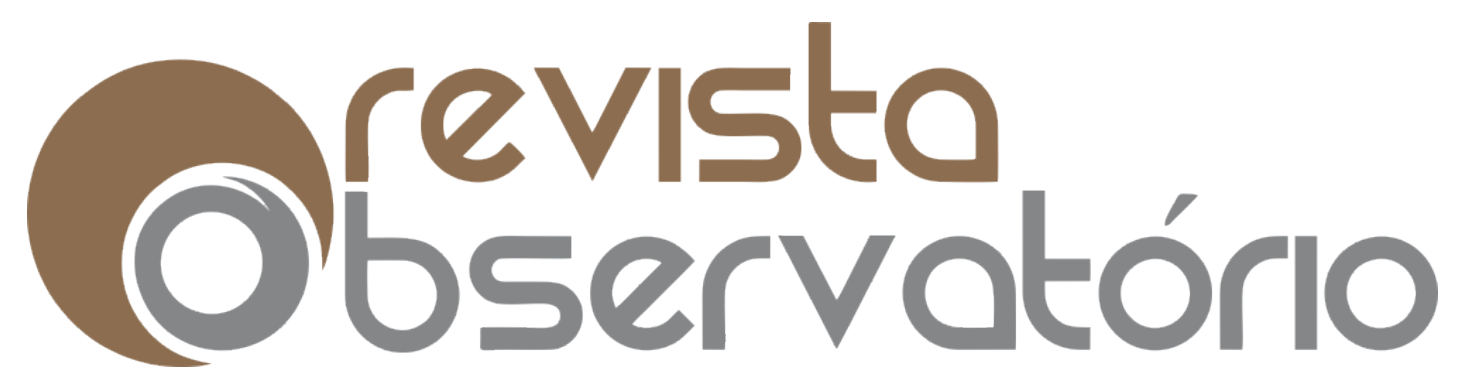

ISSN n² 2447-4266

Vol. 5, n. 5, Agosto. 2019

DOI: http://dx.doi.org/10.20873/uft.2447-4266.2019v5n5p426

forma contribuir para a construção e transmissão do conhecimento. Pois segundo Freire (1989), o educador e o educando são sujeitos do processo de educação, dessa forma, ambos crescem juntos nessa perspectiva.

Para melhorar o ensino, de acordo com CHICKERING e GAMSON (1991 apud Santos, 2001, pag. 5) foram criados os sete princípios para boa pratica da educação superior, que nada mais é que a constatação que tem como motivação o ponto de vista pratica e minucioso resultante de anos de pesquisa em faculdades e universidades americanas, e são eles:

$1^{\circ}$. A boa prática encoraja o contato entre professor e aluno - os professores que encorajam o contato com os alunos, mantêm os motivados dentro e fora da sala de aula, tornando os mais comprometidos e com melhor desenvolvimento pessoal e intelectual.

$2^{\circ}$. A boa prática encoraja a cooperação entre os alunos - o esforço do resultado em equipe é mais favorecido do que o individual, o envolvimento com outras pessoas aumenta a produtividade e ensina a dividir ideias.

$3^{\circ}$. A boa prática encoraja a aprendizagem ativa - o aluno tem que sair da postura passiva onde desempenha o papel de ouvir, memorizar os conceitos e emitir respostas, mas falar, escrever e ter atitude para ser um agente protagonista nesse processo. Isso pode ser grupo ou individualmente para que isso ocorra.

$4^{\circ}$. A boa prática fornece um feedback imediato - durante toda a vida acadêmica o aluno deve saber identificar o que já aprendeu, o que ainda precisa aprender e fazer essa reflexão, lembrando que o mais importante é ter uma resposta quanto a isso e não apenas uma medição de resultados entendendo que este é um método continuo.

$5^{\circ}$. A boa prática enfatiza o tempo da tarefa - aprender a usar bem o tempo, utilizando-o de forma satisfatória e alcançar os objetivos propostos dentro do 


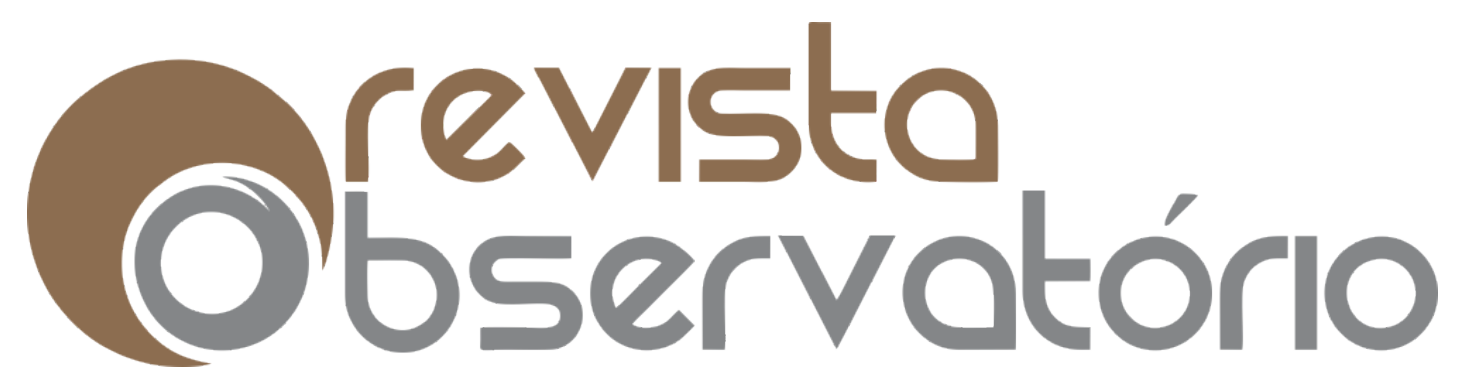

ISSN n² 2447-4266

Vol. 5, n. 5, Agosto. 2019

DOI: http://dx.doi.org/10.20873/uft.2447-4266.2019v5n5p426

prazo estipulado no planejamento da grade curricular desenvolvendo todas as tarefas necessárias para o cumprimento do conteúdo.

$6^{\circ}$. A boa prática comunica altas expectativas - os esforços e expectativas dos professores transpassam e criam um clima desafiador para o aluno que dão maior valor para as matérias mais difíceis e exigem mais interesse e dedicação.

$7^{\circ}$. A boa prática respeita os diversos talentos e as diferentes formas de aprendizagem - os professores devem reconhecer que existem diversas formas e estilos de aprendizado e que isso pode ter relação direta com a motivação, integração com a sociedade, desenvolvimento intelectual, entre outras, fazendo o professor variar continuamente seus métodos e técnicas objetivando satisfazer os diferentes tipos de alunos e ser sensível respeitando a individualidade de cada um.

Estes princípios contribuem para compreensão e melhoria do processo ensino aprendizagem. Os mesmos são adequados a qualquer curso e a qualquer tipo de aluno.

O espaço físico escolar também possui grande relevância para todos que desfrutar deste, seja como aluno ou professor, uma vez que este será local diário de estudo, discussões, debates, reflexões, convívios sociais e de lazer. Devendo este ser convidativo, representando relações de afetividade, que pode se manifestar através de observação visual e também estética. Torna-se mais agradável e prazeroso está em um ambiente que atenda a todas as necessidades e que colabore para um melhor desenvolvimento.

\section{Procedimentos Metodológicos}

O presente estudo teve abordagem quali-quantitativa para seu desenvolvimento, seu objetivo é medir o nível de satisfação dos acadêmicos do curso de Tecnólogo em Logística da Universidade Federal do Tocantins Campus 


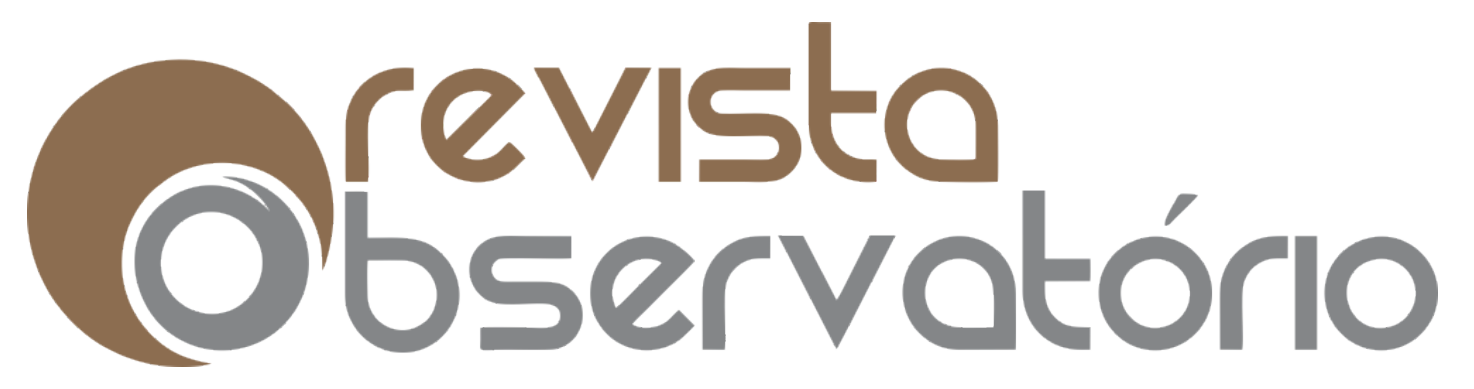

ISSN n² 2447-4266

Vol. 5, n. 5, Agosto. 2019

DOI: http://dx.doi.org/10.20873/uft.2447-4266.2019v5n5p426

Araguaína em relação as disciplinas ministradas, a didática utilizada e a infraestrutura oferecidas pela Universidade. Por isso, neste artigo foi utilizada a abordagem qualitativa, conforme Malhotra (2001, p. 155), "é uma metodologia de pesquisa não-estruturada, exploratória, baseada em pequenas amostras que proporcionam insights e compreensão do contexto do problema".

Roesch (1999) afirma dizendo que na pesquisa qualitativa o pesquisador, utilizando-se de perguntas, pode colher as expectativas dos entrevistados. Após a coleta dos dados realizada no primeiro momento, houve a necessidade de quantificar as impressões colhidas na pesquisa qualitativa. Os depoimentos foram transformados em números para medir o significado das respostas, que traz uma melhor compreensão. Quanto ao tipo da pesquisa é definida como bibliográfica por utiliza-se de opiniões de autores renomados e estudiosos nesta área, e também foi empregada a pesquisa de campo onde através de um questionário elaborado com perguntas fechadas foi determinado o nível de satisfação dos entrevistados.

\section{Análise dos Resultados}

Foram aplicados três questionários, sendo: um relacionado aos processos didáticos utilizados pelos professores que constavam num total de 11(onze) perguntas; o segundo referia-se ao relacionamento dos professores com os alunos que tinham 8(oito) perguntas e o terceiro apresentava 11(onze) questões a respeito da infraestrutura do campus da universidade. A coleta de dados foi realizada no período de nove a treze de maio de dois mil e dezesseis no turno matutino e noturno. Nesta pesquisa utilizou-se uma amostra de 44 alunos do curso de Gestão em Tecnologia em Logística. Foram colocados no quadro, os 


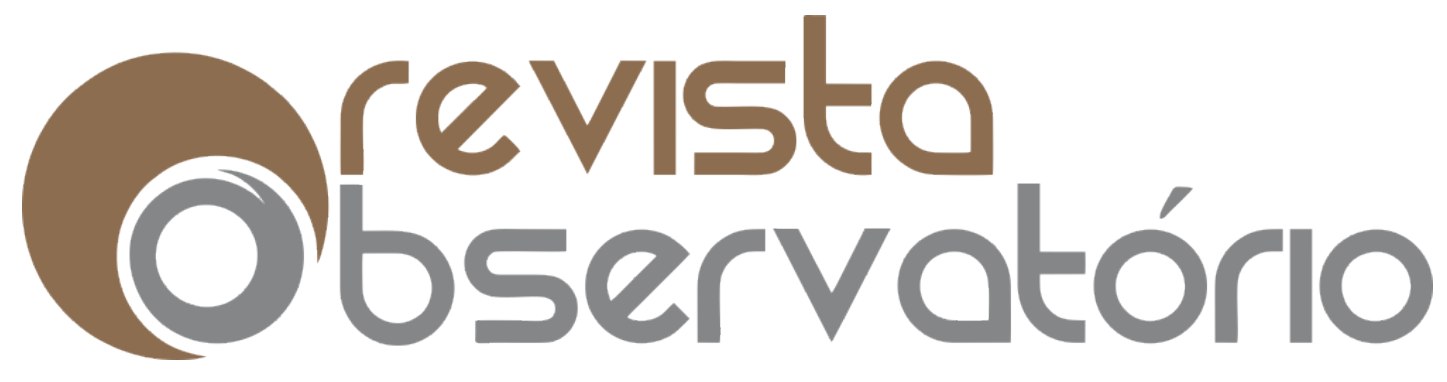

ISSN n² 2447-4266

Vol. 5, n. 5, Agosto. 2019

DOI: http://dx.doi.org/10.20873/uft.2447-4266.2019v5n5p426

percentuais de maior incidência. O quadro abaixo demonstra de forma detalhada

o resultado:

\begin{tabular}{|c|c|c|c|c|c|c|c|}
\hline \multicolumn{8}{|c|}{ PROCESSOS DIDÁTICOS } \\
\hline Afirmação & $\begin{array}{c}\text { CLAREZA } \\
\text { E } \\
\text { OBJETIVIDADE }\end{array}$ & $\begin{array}{l}\text { CUMPRI } \\
\text { MENTO DOS } \\
\text { HORÁRIOS }\end{array}$ & $\begin{array}{l}\text { USO DE } \\
\text { DIFEREN } \\
\text { TES } \\
\text { RECURSOS }\end{array}$ & $\begin{array}{c}\text { DEMONS } \\
\text { TRAÇÃO DE } \\
\text { SEGURAN } \\
\text { ÇAE } \\
\text { DOMÍNIO } \\
\text { DO } \\
\text { CONTEÚDO }\end{array}$ & $\begin{array}{l}\text { PROMO } \\
\text { ÇÃO DA } \\
\text { INTERA } \\
\text { ÇÃO NA } \\
\text { AULA }\end{array}$ & $\begin{array}{c}\text { UTILIZA } \\
\text { ÇÃO DAS } \\
\text { VÁRIAS } \\
\text { FORMAS DE } \\
\text { AVALIA } \\
\text { ÇÃO }\end{array}$ & $\begin{array}{c}\text { ESTIMULA A } \\
\text { RELAÇÃO } \\
\text { DA TEORIA } \\
\text { COM A } \\
\text { PRÁTICA }\end{array}$ \\
\hline (A) $\downarrow$ & $\begin{array}{c}41,18 \% \\
\text { Concordam }\end{array}$ & $\begin{array}{c}52,94 \% \\
\text { Concorda } \\
m\end{array}$ & $\begin{array}{c}47,07 \% \\
\text { Concorda } \\
m\end{array}$ & $\begin{array}{c}41,18 \% \\
\text { Concordam }\end{array}$ & $\begin{array}{c}32,35 \% \\
\text { Concorda } \\
m\end{array}$ & $\begin{array}{c}32,35 \% \\
\text { Concorda } \\
m\end{array}$ & $\begin{array}{c}44,12 \% \\
\text { Concorda } \\
\text { m }\end{array}$ \\
\hline (B) & $\begin{array}{c}28,00 \% \\
\text { Concordam }\end{array}$ & $\begin{array}{c}52,00 \% \\
\text { Concorda } \\
m\end{array}$ & $\begin{array}{c}52,00 \% \\
\text { Concorda } \\
m\end{array}$ & $\begin{array}{c}32,00 \% \\
\text { Concordam }\end{array}$ & $\begin{array}{c}40,00 \% \\
\text { Concorda } \\
m\end{array}$ & $\begin{array}{c}40,00 \% \\
\text { Concorda } \\
m\end{array}$ & $\begin{array}{c}40,00 \% \\
\text { Concorda } \\
m\end{array}$ \\
\hline (C) & $\begin{array}{c}73,68 \% \\
\text { Concordam }\end{array}$ & $\begin{array}{c}63,16 \% \\
\text { Concorda } \\
m\end{array}$ & $\begin{array}{c}81,58 \% \\
\text { Concorda } \\
m\end{array}$ & $\begin{array}{c}92,11 \% \\
\text { Concordam }\end{array}$ & $\begin{array}{c}81,58 \% \\
\text { Concorda } \\
m\end{array}$ & $\begin{array}{c}63,16 \% \\
\text { Concorda } \\
m\end{array}$ & $\begin{array}{c}86,84 \% \\
\text { Concorda } \\
m\end{array}$ \\
\hline (D) & $\begin{array}{c}70,59 \% \\
\text { Concordam }\end{array}$ & $\begin{array}{c}67,65 \% \\
\text { Concorda } \\
m\end{array}$ & $\begin{array}{c}32,35 \% \\
\text { Concorda }\end{array}$ & $\begin{array}{c}79,41 \% \\
\text { Concordam }\end{array}$ & $\begin{array}{c}38,24 \% \\
\text { Concorda } \\
m\end{array}$ & $\begin{array}{c}26,47 \% \\
\text { Concorda } \\
m\end{array}$ & $\begin{array}{c}64,71 \% \\
\text { Concorda } \\
m\end{array}$ \\
\hline
\end{tabular}

\begin{tabular}{|c|c|c|c|c|c|c|c|}
\hline \multicolumn{8}{|c|}{ PROCESSOS DIDÁTICOS } \\
\hline Afirmação & $\begin{array}{c}\text { CLAREZA } \\
E \\
\text { OBJETIVIDADE }\end{array}$ & $\begin{array}{c}\text { CUMPRI } \\
\text { MENTO DOS } \\
\text { HORÁRIOS }\end{array}$ & $\begin{array}{l}\text { USO DE } \\
\text { DIFEREN } \\
\text { TES } \\
\text { RECURSOS }\end{array}$ & $\begin{array}{c}\text { DEMONS } \\
\text { TRAÇÃO DE } \\
\text { SEGURAN } \\
\text { ÇA E } \\
\text { DOMÍNIO } \\
\text { DO } \\
\text { CONTEÚDO }\end{array}$ & $\begin{array}{l}\text { PROMO } \\
\text { ÇÃO DA } \\
\text { INTERA } \\
\text { ÇÃO NA } \\
\text { AULA }\end{array}$ & $\begin{array}{c}\text { UTILIZA } \\
\text { ÇÃO DAS } \\
\text { VÁRIAS } \\
\text { FORMAS DE } \\
\text { AVALIA } \\
\text { ÇÃO }\end{array}$ & $\begin{array}{c}\text { ESTIMULA A } \\
\text { RELAÇÃO } \\
\text { DA TEORIA } \\
\text { COM A } \\
\text { PRÁTICA }\end{array}$ \\
\hline (E) $\downarrow$ & $\begin{array}{c}35,29 \% \\
\text { Concordam }\end{array}$ & $\begin{array}{c}38,24 \% \\
\text { Concorda } \\
m\end{array}$ & $\begin{array}{c}38,24 \% \\
\text { Concorda } \\
m\end{array}$ & $\begin{array}{c}41,18 \% \\
\text { Concordam }\end{array}$ & $\begin{array}{c}38,24 \% \\
\text { Concorda } \\
m\end{array}$ & $\begin{array}{c}29,41 \% \\
\text { Concorda } \\
m\end{array}$ & $\begin{array}{c}32,35 \% \\
\text { Concorda } \\
m\end{array}$ \\
\hline (F) & $\begin{array}{c}62,86 \% \\
\text { Concordam }\end{array}$ & $\begin{array}{c}51,43 \% \\
\text { Concorda } \\
m\end{array}$ & $\begin{array}{c}51,43 \% \\
\text { Concorda } \\
m\end{array}$ & $\begin{array}{c}42,86 \% \\
\text { Concordam }\end{array}$ & $\begin{array}{c}51,43 \% \\
\text { Concorda } \\
m\end{array}$ & $\begin{array}{c}37,14 \% \\
\text { Concorda } \\
m\end{array}$ & $\begin{array}{c}42,86 \% \\
\text { Concorda } \\
m\end{array}$ \\
\hline (G) & $\begin{array}{c}67,86 \% \\
\text { Concordam }\end{array}$ & $\begin{array}{c}53,57 \% \\
\text { Concorda } \\
m\end{array}$ & $\begin{array}{c}53,57 \% \\
\text { Concorda } \\
m\end{array}$ & $\begin{array}{c}64,29 \% \\
\text { Concordam }\end{array}$ & $\begin{array}{c}53,57 \% \\
\text { Concorda } \\
m\end{array}$ & $\begin{array}{c}46,43 \% \\
\text { Concorda } \\
m\end{array}$ & $\begin{array}{c}42,86 \% \\
\text { Concorda } \\
m\end{array}$ \\
\hline
\end{tabular}




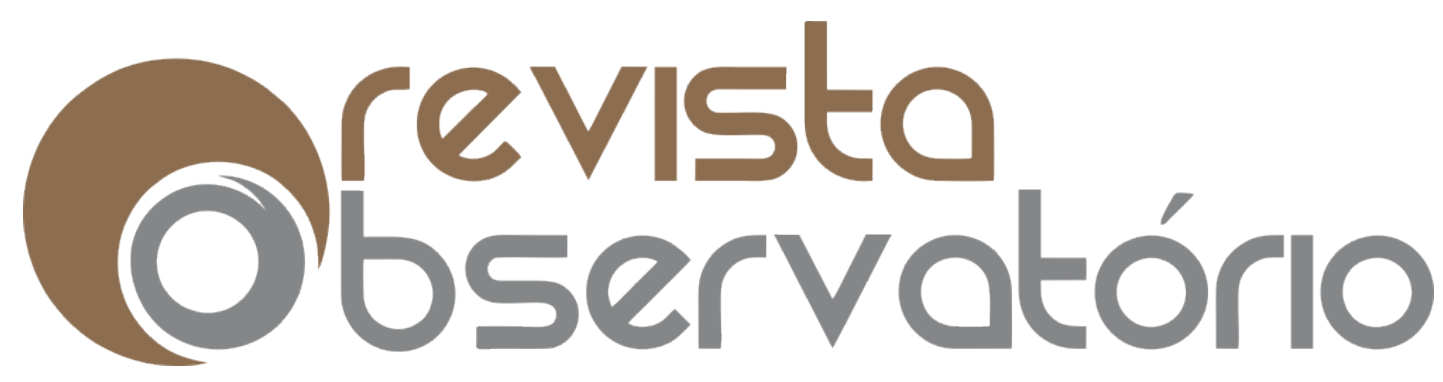

ISSN n² 2447-4266

Vol. 5, n. 5, Agosto. 2019

DOI: http://dx.doi.org/10.20873/uft.2447-4266.2019v5n5p426

\begin{tabular}{|l|c|c|c|c|c|c|c|}
\hline $\mathrm{H})$ & $\begin{array}{c}31,58 \% \\
\text { Concordam }\end{array}$ & $\begin{array}{c}47,37 \% \\
\text { Concorda } \\
\mathrm{m}\end{array}$ & $\begin{array}{c}36,84 \% \\
\text { Concorda } \\
\mathrm{m}\end{array}$ & $\begin{array}{c}31,58 \% \\
\text { Concordam }\end{array}$ & $\begin{array}{c}42,11 \% \\
\text { Concorda } \\
\mathrm{m}\end{array}$ & $\begin{array}{c}31,58 \% \\
\text { Concorda } \\
\mathrm{m}\end{array}$ & $\begin{array}{c}42,11 \% \\
\text { Concorda } \\
\mathrm{m}\end{array}$ \\
\hline
\end{tabular}

Quadro2: Procedimentos Didáticos

Fonte: Elaboração própria

Em relação aos processos didáticos, as variações de percentual em relação à clareza e objetividade obedeceram a uma máxima de 73,68\% e uma mínima de $28 \%$. A maior parte dos professores conseguem se expressar de modo a passar para seus alunos os conteúdos pré-estabelecidos de forma clara e objetiva em suas aulas. Como proposta, seria necessário um treinamento ou oficinas pedagógicas continuas para ser trabalhada a forma de se comunicar e se expressar de modo que esta seja utilizada como a ferramenta indispensável no processo de ensino e aprendizagem.

Quanto ao cumprimento dos horários o maior índice foi $67,65 \%$ e o menor de $38,24 \%$ apontando que, grande parte dos professores seguem os horários cumprindo-os fielmente, tanto de início como do final de cada aula; no quesito relacionado ao uso de diferentes recursos (vídeos, discussão, seminários, estudo de caso, visitas técnicas, etc.) como estratégias para ministrar as aulas $81,58 \%$ foi o índice mais elevado e $32,35 \%$ o menor, isso afirma que os professores deverão deixar para traz as aulas monótonas e cansativas e utilizar técnicas novas, diversificar suas aulas, fazer com que elas sejam mais motivadoras, interessantes, e chamem mais a atenção dos alunos, possibilitando uma melhor assimilação e entendimento do conteúdo. Como sugestões deveriam acontecer cursos, oficinas e até conversas entre os próprios professores onde poderão trocar conhecimentos e experiências, uma vez que alguns professores tiveram um índice muito alto quanto esse item e estes podem repassar suas técnicas para os colegas, além de utilizar métodos como jogos, grupos de discussão, simulações, estudos de caso e laboratórios. 


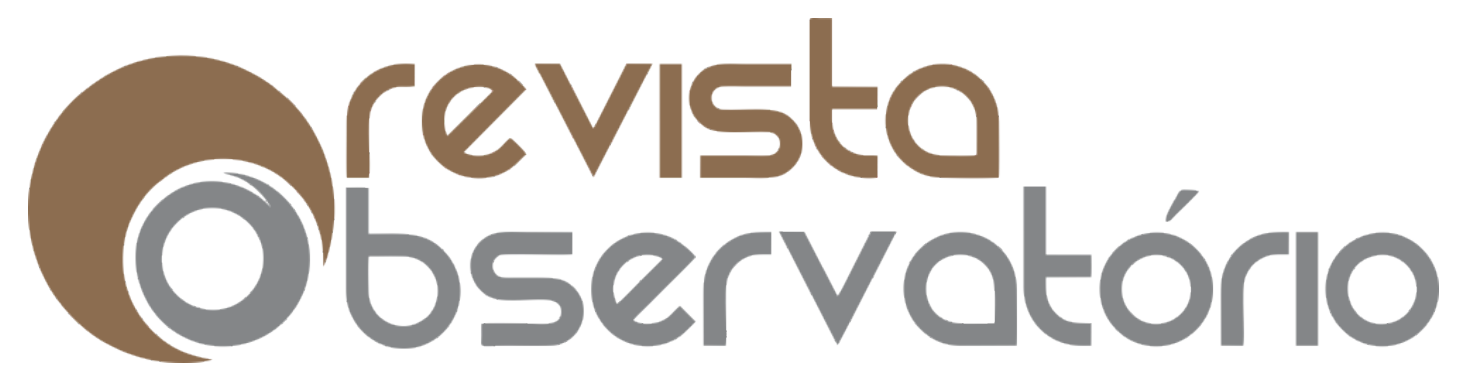

ISSN n² 2447-4266

Vol. 5, n. 5, Agosto. 2019

DOI: http://dx.doi.org/10.20873/uft.2447-4266.2019v5n5p426

Os percentuais aferidos para segurança e domínio do conteúdo foram: $92,11 \%$ como o maior e $31,58 \%$ como o menor, isso demonstra que os docentes em sua maioria demonstram conhecimento e afinidade com os assuntos e matérias ministradas, passando confiança para seus alunos. Como recomendação fica de inteirar-se com os assuntos e buscar conhecimento a respeito para que isso possa dar suporte e argumentação na discussão dos temas e proporcionar segurança e experiência na docência que também contribuirá de forma positiva para essa situação ser contornada.

Quanto à interação nas aulas foi obtido um percentual de $81,58 \%$ como o índice máximo e 32,35\% de mínimo, permitindo afirmar que os professores promovem a interação, proporcionando, assim, a troca de conhecimentos e experiências dos alunos no momento em que ministram suas aulas, mas que isso pode ser melhorado e promovido pelo professor, utilizando técnicas que estimulem o pensamento, questionamento e a discussão sobre assuntos relevantes.

No que diz respeito às formas de avaliação utilizadas pelos professores, foi observado como maior índice $63,16 \%$ e como menor de $26,47 \%$, os números asseguram dizer que precisa urgentemente modificar ou reformular a maneira como é feita a pontuação das notas, deixar de utilizar apenas uma maneira e realizar outras atividades que também possam trazer pontuação no decorrer do semestre, dividindo o peso das notas para atingir a média estabelecida para aprovação na matéria, este foi o menor índice obtido na coleta de dados desta pesquisa e merece um maior cuidado ao ser analisado.

Para o item referente à relação teoria e prática dos conteúdos foi apurado como índice máximo $86,84 \%$, este item se manteve equilibrado para todos os 


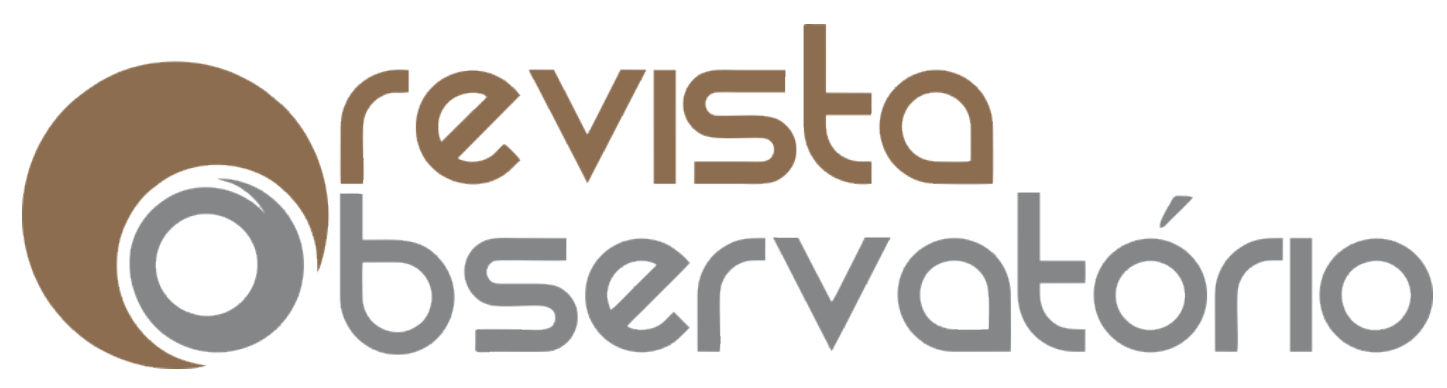

ISSN n² 2447-4266

Vol. 5, n. 5, Agosto. 2019

DOI: http://dx.doi.org/10.20873/uft.2447-4266.2019v5n5p426

professores o que permite apontar a existência da associação da teoria e prática. Mais como sugestões deverão usar mais exemplos práticos de empresas da região e acontecer mais visitas nas mesmas, promover pesquisas de campo, ter mais proximidade das atividades desenvolvidas pela logística.

Já no quadro 3 estão representados em números de maior ocorrência na opinião dos alunos no que diz respeito ao relacionamento existente entre os professores e os alunos.

\begin{tabular}{|c|c|c|c|c|c|c|c|}
\hline \multicolumn{8}{|c|}{ RELACIONAMENTO COM ALUNO } \\
\hline EIXOS & $\begin{array}{l}\text { POSTURA } \\
\text { ÉTICA } \\
\text { RESPEITO }\end{array}$ & $\begin{array}{l}\text { PREOCUPA } \\
\text { ÇÃO COM } \\
\text { APRENDI } \\
\text { ZAGEM DOS } \\
\text { ALUNOS }\end{array}$ & $\begin{array}{l}\text { ATENÇÃO E } \\
\text { DISPOSI } \\
\text { ÇÃO PARA } \\
\text { AUUDAR }\end{array}$ & $\begin{array}{l}\text { CONSIDE } \\
\text { RAÇÃO } \\
\text { QUANTO A } \\
\text { INDIVIDUALI } \\
\text { DADE DE } \\
\text { CADA UM }\end{array}$ & $\begin{array}{l}\text { PARTICI } \\
\text { PAÇÃO EM } \\
\text { ATIVIDA } \\
\text { DES EXTRA } \\
\text { CLASSES }\end{array}$ & $\begin{array}{l}\text { ABERTURA A } \\
\text { NOVAS } \\
\text { IDÉIAS }\end{array}$ & $\begin{array}{l}\text { TRATA } \\
\text { MENTO DE } \\
\text { FORMA } \\
\text { CORDIAL }\end{array}$ \\
\hline$(\mathrm{A})$ & $\begin{array}{c}73,53 \% \\
\text { Concorda } \\
m\end{array}$ & $\begin{array}{c}38,24 \% \\
\text { Concorda } \\
m\end{array}$ & $\begin{array}{c}44,12 \% \\
\text { Concorda } \\
m\end{array}$ & $\begin{array}{c}32,35 \% \\
\text { Concorda } \\
m\end{array}$ & $\begin{array}{c}26,47 \% \\
\text { Concorda } \\
m\end{array}$ & $\begin{array}{c}41,18 \% \\
\text { Concorda } \\
m\end{array}$ & $\begin{array}{c}47,06 \% \\
\text { Concorda } \\
m\end{array}$ \\
\hline (B) & $\begin{array}{c}64,00 \% \\
\text { Concorda } \\
m\end{array}$ & $\begin{array}{c}48,00 \% \\
\text { Concorda } \\
m\end{array}$ & $\begin{array}{c}52,00 \% \\
\text { Concorda } \\
m\end{array}$ & $\begin{array}{c}32,00 \% \\
\text { Concorda } \\
m\end{array}$ & $\begin{array}{c}48,00 \% \\
\text { Concorda } \\
m\end{array}$ & $\begin{array}{c}56,00 \% \\
\text { Concorda } \\
m\end{array}$ & $\begin{array}{c}60,00 \% \\
\text { Concorda } \\
m\end{array}$ \\
\hline (C) & $\begin{array}{c}73,68 \% \\
\text { Concorda } \\
m\end{array}$ & $\begin{array}{c}47,68 \% \\
\text { Concorda } \\
m\end{array}$ & $\begin{array}{c}50,00 \% \\
\text { Concorda } \\
m\end{array}$ & $\begin{array}{c}34,21 \% \\
\text { Concorda } \\
m\end{array}$ & $\begin{array}{c}65,79 \% \\
\text { Concorda } \\
m\end{array}$ & $\begin{array}{c}63,16 \% \\
\text { Concorda } \\
m\end{array}$ & $\begin{array}{c}63,16 \% \\
\text { Concorda } \\
m\end{array}$ \\
\hline (D) & $\begin{array}{c}79,41 \% \\
\text { Concorda } \\
m\end{array}$ & $\begin{array}{c}50,00 \% \\
\text { Concorda } \\
m\end{array}$ & $\begin{array}{c}55,88 \% \\
\text { Concorda } \\
m\end{array}$ & $\begin{array}{c}32,35 \% \\
\text { Concorda } \\
m\end{array}$ & $\begin{array}{c}47,06 \% \\
\text { Concorda } \\
m\end{array}$ & $\begin{array}{c}47,06 \% \\
\text { Concorda } \\
m\end{array}$ & $\begin{array}{c}58,85 \% \\
\text { Concorda } \\
m\end{array}$ \\
\hline$(\mathrm{E})$ & $\begin{array}{c}52,94 \% \\
\text { Concorda } \\
m\end{array}$ & $\begin{array}{c}47,06 \% \\
\text { Concorda } \\
m\end{array}$ & $\begin{array}{c}38,24 \% \\
\text { Concorda } \\
m\end{array}$ & $\begin{array}{c}38,24 \% \\
\text { Concorda } \\
m\end{array}$ & $\begin{array}{c}32,35 \% \\
\text { Concorda } \\
m\end{array}$ & $\begin{array}{c}44,12 \% \\
\text { Concorda } \\
m\end{array}$ & $\begin{array}{c}50,00 \% \\
\text { Concorda } \\
m\end{array}$ \\
\hline
\end{tabular}




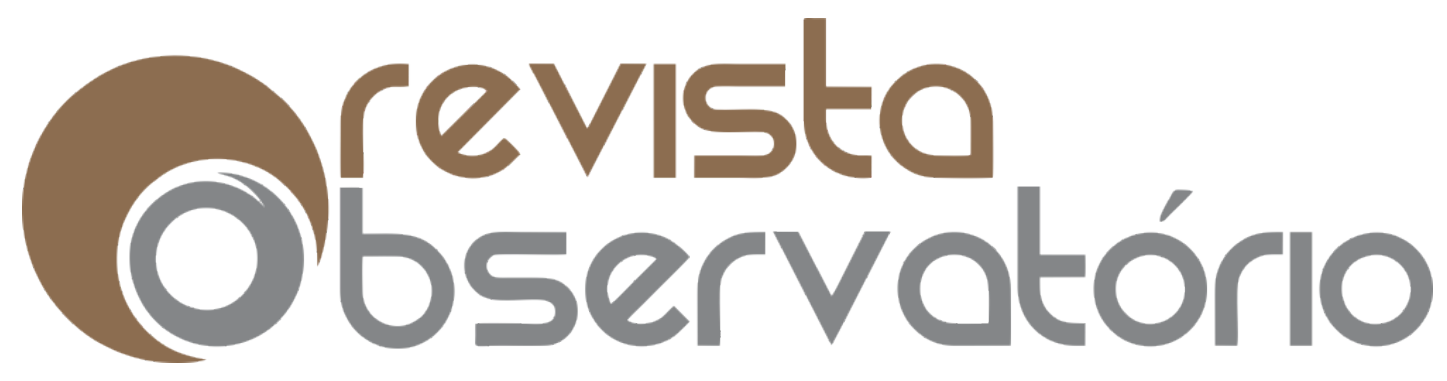

ISSN n² 2447-4266

Vol. 5, n. 5, Agosto. 2019

DOI: http://dx.doi.org/10.20873/uft.2447-4266.2019v5n5p426

\begin{tabular}{|c|c|c|c|c|c|c|c|}
\hline$(\mathrm{F})$ & $\begin{array}{c}65,71 \% \\
\text { Concorda } \\
\mathrm{m}\end{array}$ & $\begin{array}{c}40,00 \% \\
\text { Concorda } \\
\mathrm{m}\end{array}$ & $\begin{array}{c}48,57 \% \\
\text { Concorda } \\
\mathrm{m}\end{array}$ & $\begin{array}{c}42,86 \% \\
\text { Concorda } \\
\mathrm{m}\end{array}$ & $\begin{array}{c}40,00 \% \\
\text { Concorda } \\
\mathrm{m}\end{array}$ & $\begin{array}{c}48,57 \% \\
\text { Concorda } \\
\mathrm{m}\end{array}$ & $\begin{array}{c}60,00 \% \\
\text { Concorda } \\
\mathrm{m}\end{array}$ \\
\hline$(\mathrm{G})$ & $\begin{array}{c}67,86 \% \\
\text { Concorda } \\
\mathrm{m}\end{array}$ & $\begin{array}{c}46,43 \% \\
\text { Concorda } \\
\mathrm{m}\end{array}$ & $\begin{array}{c}53,57 \% \\
\text { Concorda } \\
\mathrm{m}\end{array}$ & $\begin{array}{c}53,57 \% \\
\text { Concorda } \\
\mathrm{m}\end{array}$ & $\begin{array}{c}53,57 \% \\
\text { Concorda } \\
\mathrm{m}\end{array}$ & $\begin{array}{c}57,14 \% \\
\text { Concorda } \\
\mathrm{m}\end{array}$ & $\begin{array}{c}53,57 \% \\
\text { Concorda } \\
\mathrm{m}\end{array}$ \\
\hline$(\mathrm{H})$ & $\begin{array}{c}47,37 \% \\
\text { Concorda } \\
\mathrm{m}\end{array}$ & $\begin{array}{c}42,11 \% \\
\text { Concorda } \\
\mathrm{m}\end{array}$ & $\begin{array}{c}36,84 \% \\
\text { Concorda } \\
\mathrm{m}\end{array}$ & $\begin{array}{c}26,32 \% \\
\text { Concorda } \\
\mathrm{m}\end{array}$ & $\begin{array}{c}31,58 \% \\
\text { Concorda } \\
\mathrm{m}\end{array}$ & $\begin{array}{c}52,63 \% \\
\text { Concorda } \\
\mathrm{m}\end{array}$ & $\begin{array}{c}47,37 \% \\
\text { Concorda } \\
\mathrm{m}\end{array}$ \\
\hline
\end{tabular}

Quadro 3: Relacionamento com aluno

Fonte: Elaboração própria

Quanto ao item postura e a ética dos professores o maior índice apurado foi $79,41 \%$ e o menor foi $47,37 \%$ o que permite afirmar que os alunos concordam que eles assumem totalmente uma postura pautada no respeito e na ética profissional e pessoal, tendo uma conduta que obedece aos padrões e valores, tanto da sociedade, quanto da própria universidade.

Na avaliação da preocupação com a aprendizagem dos alunos, a máxima foi $50 \%$ e a mínima $38,24 \%$, os números demonstram que os alunos não percebem que exista atenção e o cuidado por parte dos professores em relação à transmissão do conhecimento de forma que todos compreendam e assim proporcione de forma ampla a aprendizagem de todos os alunos. Como sugestão deveria existir um pouco de diálogo a este respeito, para que os alunos entendam o quanto é importante para os professores que seus alunos compreendam e entendam o conhecimento o qual eles estão repassando e o dever que eles têm de se comprometer com o próprio desenvolvimento contínuo e se comportar de maneira a alcançar suas metas pessoais e objetivos da universidade desempenhando sua função de ensinar com excelência, automaticamente estarão contribuindo com o todo. E que tudo isso é refletido no desempenho dos alunos. 


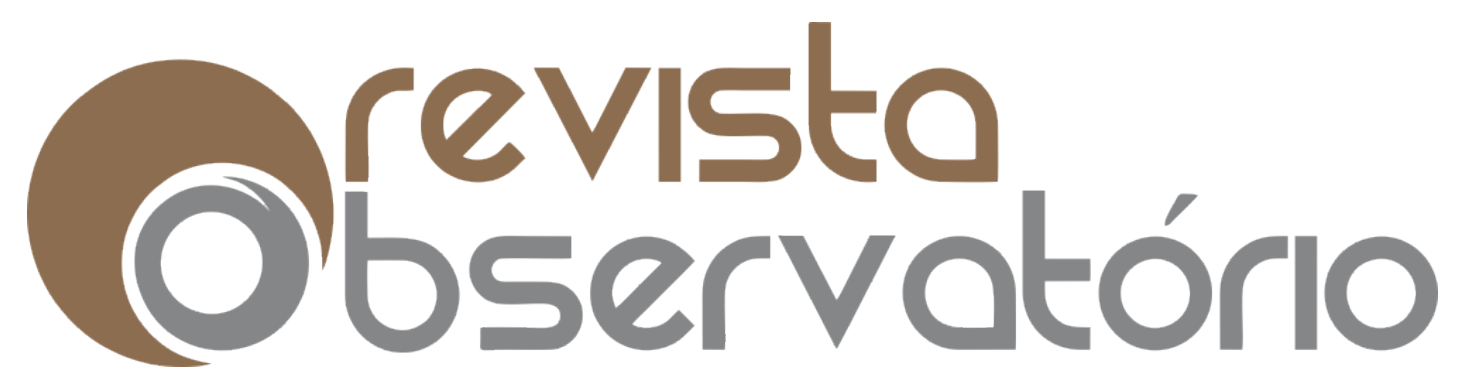

ISSN n² 2447-4266

Vol. 5, n. 5, Agosto. 2019

DOI: http://dx.doi.org/10.20873/uft.2447-4266.2019v5n5p426

Para o item atenção e disposição para ajudar foi aferido os percentuais $55,88 \%$ como o maior e de $36,84 \%$ o menor, os alunos concordam que a maioria dos professores possuem vontade de ajudar e disponibilizam horários destinados exclusivamente para auxiliar seus alunos, além de que são acessíveis tanto no campus como por meios digitais de comunicação.

Em relação à consideração da individualidade opinaram 53,57\% na sua maioria e o menor índice foi $26,32 \%$ dos respondentes dizem que os professores consideram a individualidade de cada um, a maneira exclusiva que cada aluno tem em relação ao grupo, quanto à forma e o tempo que cada um aprende.

Com relação à participação de atividades extraclasse foi conferido que o maior percentual foi $65,79 \%$ e o menor $26,47 \%$ observa-se que os índices se mantiveram bem estáveis independentes dos professores, isso significa que os professores pouco participam desse tipo de atividade e deverão ser planejadas, organizadas e implementadas com maior frequência no curso, mais que para isso acontecer e necessário total cooperação, envolvimento e participação dos professores inclusive para incentivar os alunos.

$\mathrm{Na}$ questão do professor estar aberto às novas ideias, que não é apenas tolerar opiniões distintas, mas ter diferentes formas de pensar sobre diversas questões, que podem gerar indagações que levam à uma melhor tomada de decisão, uma maior criatividade pessoal, e pode até ajudar a reafirmar posições com clareza ou apenas reafirmar ideias atuais.

As porcentagens aferidas quanto ao tratamento da forma cordial foi $63,16 \%$ foram à máxima e $47,06 \%$ a mínima, os alunos comprovam que os professores são sempre cordiais, sendo educados, afetuosos, amigáveis, tornando a relação sempre mais fácil e amistosa para ambas as partes. 


\section{Observisto}

ISSN n² 2447-4266

Vol. 5, n. 5, Agosto. 2019

DOI: http://dx.doi.org/10.20873/uft.2447-4266.2019v5n5p426

O quadro 4 apresenta o entendimento dos alunos no tocante a infraestrutura do Campus Cimba que segue demonstrando apenas o índice que obteve um percentual com maior ocorrência:

\begin{tabular}{|c|c|c|}
\hline \multicolumn{3}{|l|}{ INFRAESTRUTURA } \\
\hline Eixos Analisados & Satisfeito & Insatisfeito \\
\hline Quanto à iluminação das salas. & $61,36 \%$ & $38,64 \%$ \\
\hline Quanto à limpeza das salas. & $68,18 \%$ & $31,82 \%$ \\
\hline Quanto ao conforto das salas. & $65,91 \%$ & $34,09 \%$ \\
\hline $\begin{array}{l}\text { Quanto à acessibilidade inclusive para portadores } \\
\text { de necessidades especiais }\end{array}$ & $30,91 \%$ & $69,09 \%$ \\
\hline Quanto à biblioteca & $60,55 \%$ & $39,45 \%$ \\
\hline Quanto à iluminação do campus & $70,73 \%$ & $29,27 \%$ \\
\hline Quanto ao estacionamento & $52,73 \%$ & $47,27 \%$ \\
\hline Quanto ao espaço para grandes eventos & $33,18 \%$ & $66,18 \%$ \\
\hline Quanto à segurança dentro do campus & $61,94 \%$ & $38,06 \%$ \\
\hline $\begin{array}{l}\text { Quanto à quantidade e disponibilidade das salas } \\
\text { de aula }\end{array}$ & $70,45 \%$ & $29,55 \%$ \\
\hline $\begin{array}{l}\text { Quanto ao espaço dedicado a pratica de esportes } \\
\text { e ou atividades de lazer }\end{array}$ & $31,82 \%$ & $68,18 \%$ \\
\hline
\end{tabular}

Quanto às afirmações presentes nos questionários aplicados $61,36 \%$ concordam que as salas são bem iluminadas; $68,18 \%$ que estão sempre limpas; 65,91\% que são confortáveis e 70,45\% que a disposição e quantidade são suficientes para atender toda a demanda de alunos, ou seja, em relação as salas a maioria se posicionaram positivamente e aprova a maneira cada elas se apresentam. 


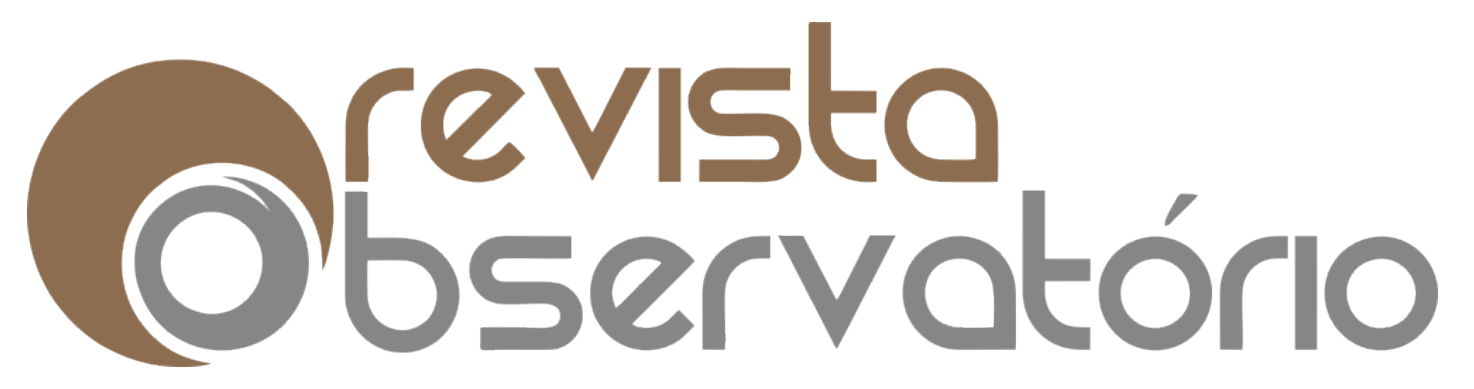

ISSN n² 2447-4266

Vol. 5, n. 5, Agosto. 2019

DOI: http://dx.doi.org/10.20873/uft.2447-4266.2019v5n5p426

Cerca de 69,09\% dos entrevistados não concordam que os blocos possuem acessibilidade, por estar mal distribuído, não possuírem cobertura caso seja necessário o deslocamento em dias chuvosos, além de existir uma dificuldade em identificá-los inclusive por curso e que é difícil andar pelo campus devido ao bloqueio de algumas áreas em consequência de obras é que isso se torna bem mais difícil para os portadores de necessidades especiais.

No que diz respeito à biblioteca $60,55 \%$ dos alunos que responderam o questionário manifestaram está satisfeito, mas que a biblioteca deveria disponibilizar uma variedade maior de publicações e que as mesmas fossem atualizadas e que poderia ser ampliado o espaço que hoje comporta uma quantidade limitada de estudantes.

Em relação à iluminação do campus 70,73\% relataram concordar que ela seja suficiente e que traga tranquilidade para quem transita pelo local, 61,94\% dos entrevistados dizem concordar que se sintam seguros dentro do campus da universidade.

No que diz respeito ao estacionamento, a maior parte dos alunos afirma que está um pouco confuso com espaço insuficiente e mal organizado e 52,73\% concordam que não tem dificuldade para estacionar seus veículos.

Quanto aos espaços dedicados a atividades especificas a grande maioria afirma que eles não existem $66,18 \%$ discorda totalmente que a UFT tenha espaço dedicado à realização de grandes eventos como a cerimônia de colação de grau, por exemplo, assim como $68,18 \%$ se manifestou contrários a afirmação de que a universidade disponibiliza um local para a prática de esportes e lazer no campus.

\section{Conclusões e Recomendações}

O presente estudo foi desenvolvido com o propósito de investigar a satisfação dos alunos do curso superior de tecnologia em logística da 


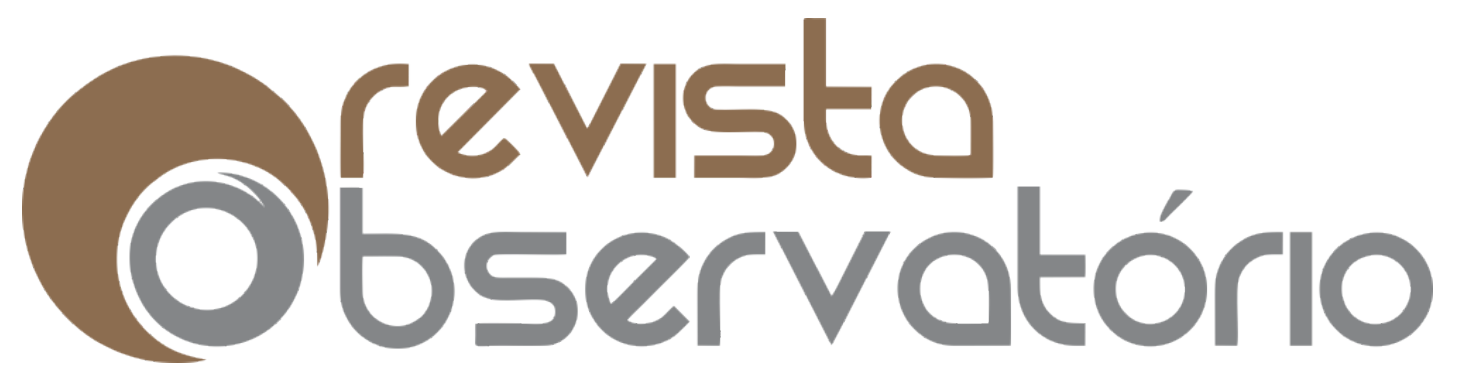

ISSN n² 2447-4266

Vol. 5, n. 5, Agosto. 2019

DOI: http://dx.doi.org/10.20873/uft.2447-4266.2019v5n5p426

Universidade Federal do Tocantins - UFT foi aplicado uma pesquisa em relação aos atributos pedagógicos dos docentes que compõem o referido curso e ao espaço físico. Para isso, foi realizada uma pesquisa de campo, mediante a aplicação de um questionário formulado com base em três eixos fundamentais: infraestrutura, ensino aprendizagem e relacionamento. Especificamente, foi analisada a opinião dos alunos em relação à infraestrutura geral da universidade examinando também a opinião dos acadêmicos com relação à qualidade do ensino, identificando a didática utilizada pelos docentes, assim como o relacionamento que existe entre os professores e alunos.

Os resultados gerados nos permitem afirmar no que se refere à clareza e objetividade os professores conseguem de forma geral se expressar de maneira que seja compreendido e que a comunicação aconteça plenamente, mas deve ser levado em consideração que alguns professores devem trabalhar um pouco mais essa questão, pois os alunos demonstram uma certa dificuldade em entender o que eles dizem ou utilizar uma linguagem menos técnica para facilitar a compreensão.

Em relação ao cumprimento de horários das aulas é notório e expressivo o resultado que atesta que os docentes seguem com rigor e pontualidade o momento que inicia e termina cada aula, não havendo faltas injustificadas e ausências repentinas, onde é comunicado com antecedência o não comparecimento e expressado os motivos por não ter determinada aula, assim como quando necessário, é realizada a reposição da mesma.

Quanto ao uso de diferentes recursos para ministrar as aulas, o percentual aferido certifica que os professores estão em sua zona de conforto e que cada um, da sua maneira oferece poucos ou quase nenhuma diversificação na aplicação de meios para proporcionar uma aula mais participativa e criativa. E que apenas um deles consegue demonstrar de inúmeras formas e ações o uso 


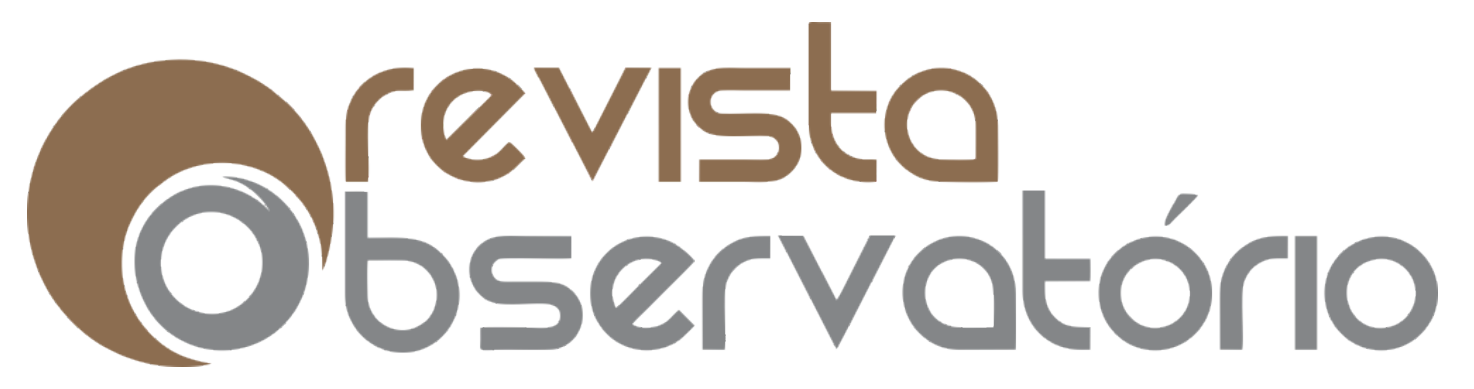

ISSN n² 2447-4266

Vol. 5, n. 5, Agosto. 2019

DOI: http://dx.doi.org/10.20873/uft.2447-4266.2019v5n5p426

de diferentes praticas para auxiliar o ensino dos conteúdos tornando suas aulas mais práticas, divertida e proveitosa.

De acordo com a pesquisa no que se refere à demonstração de segurança e domínio do conteúdo explanado poucos demonstram uma certa imaturidade que pode ser remetida a pouca experiência, e que isso pode ser sanado através de oficinas que trabalharão a segurança ao falar e discutir determinados assuntos e que a experiência adquirida com o passar do tempo também ajudará para que possa ser melhorado esse índice. No entanto, os professores que possuem um pouco mais de experiência em sala de aula, mostram total desenvoltura, desembaraço, naturalidade e sentem se completamente à vontade, isso é refletido para os alunos no decorrer das aulas.

A respeito da promoção da interação dos alunos na aula observa-se que para que aconteça de fato, é necessário, que os professores utilizem práticas que irão subsidiar e favorecer está comunicação e troca de conhecimento. O professor deverá ser o agente que conduz de maneira efetiva esse processo oportunizando os alunos a se manifestar durante o debate de assuntos nas aulas podendo expor suas ideias e opiniões. Lembrando que mesmo que discretamente, isso já ocorre em algumas aulas, mais que poderá ser realizado com maior intensidade em todas as disciplinas.

No item que se refere à utilização de vários tipos de avaliação, foi demonstrado o menor índice encontrado revelando que os alunos de modo geral apontam que os professores estão utilizando um método conservador, tradicional e único para avaliar o conhecimento do aluno, não que este seja ineficaz, mas que poderão incorporar outros aspectos para chegar à avaliação final e não cometer falhas nesse que é um dos passos fundamentais para mensurar o conhecimento obtido. 


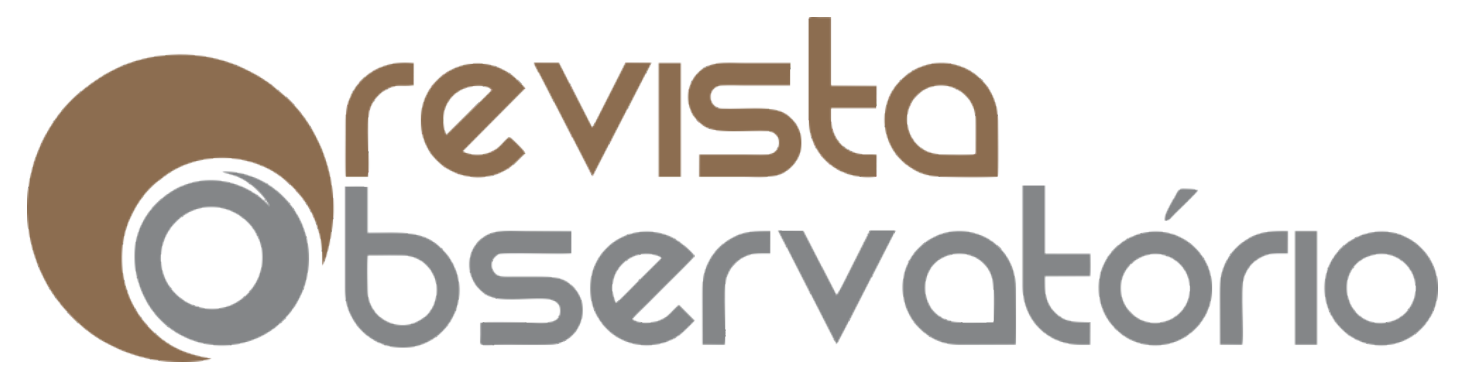

ISSN n² 2447-4266

Vol. 5, n. 5, Agosto. 2019

DOI: http://dx.doi.org/10.20873/uft.2447-4266.2019v5n5p426

Os índices apurados quanto a estimular a relação teoria e prática foram satisfatórios e poderão ser mais aplicados com exemplificação de situações reais, que sejam promovidas visitas técnicas, estudos de campo, pesquisas, pois a ação possibilita a geração de conhecimento de forma natural e duradoura. No resultado geral, os professores foram bem avaliados quanto aos seus processos didáticos, mas que podem fazer algumas reformulações e adicionar a seu portfólio uma pouco mais de opções e ousar mais da criatividade e na inovação.

Quanto ao relacionamento aluno e professor os resultados mostraram positivamente o modo como os alunos sentem essa relação, pois os professores são vistos como referências de comportamentos, valores e atitudes, levando em consideração o modelo de conduta profissional e pessoal de cada um deles. Observando a dimensão da importância de estar num local onde pode-se expor sem medo e sem receio sendo mais criativos e espontâneos.

No entanto, se a universidade promover ao acadêmico um clima o qual ele esteja à vontade para se colocar, seja em forma de palavras ou comportamentos, o aprendizado poderá ser mais proveitoso. Em respeito aos itens do questionário, foi elogiado a postura ética e profissional adotada pelos professores assim como o tratamento cordial e respeitoso que eles demonstram como seus alunos, além de transmitir atenção e pronta disposição para ajudar e auxiliar sempre que necessário, estão abertos a questionamentos e acolhimentos de novas ideias e pensamentos, mesmo que estas sejam distintas das suas, dando liberdade de expressão de opiniões, e que deverão mostrar um pouco mais a preocupação e compromisso em conseguir repassar o conhecimento para os alunos e proporcionar mais participação dentro de sala quanto em atividades extraclasse sempre respeitando a individualidade e particularidade de cada um.

Os resultados obtidos sobre a infraestrutura do campus não foram satisfatório, pois, ressalvando apenas o item relativo à limpeza, iluminação, 


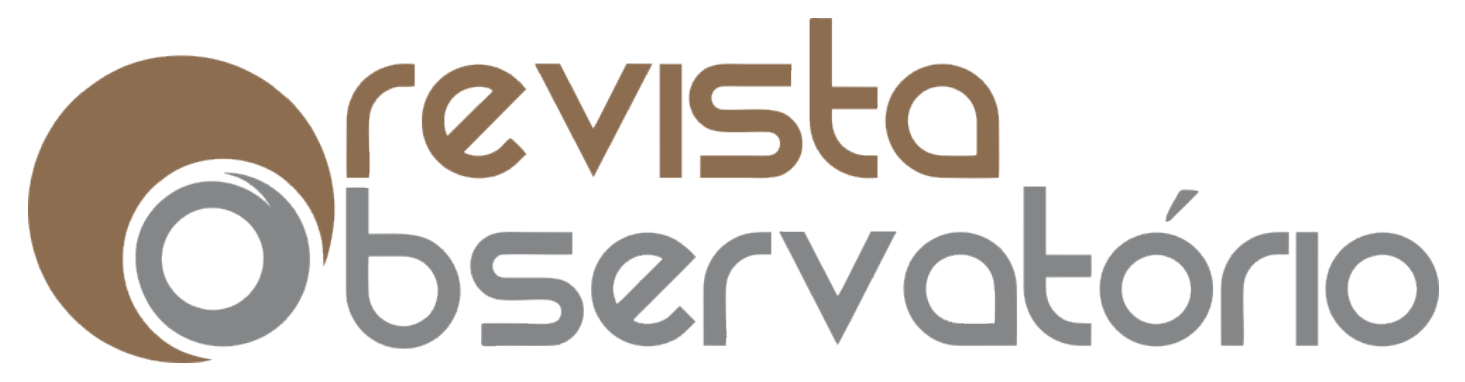

ISSN n² 2447-4266

Vol. 5, n. 5, Agosto. 2019

DOI: http://dx.doi.org/10.20873/uft.2447-4266.2019v5n5p426

conforto, quantidade e disposição das salas de aulas, que tiveram um índice mediano onde as condições são consideradas aceitável para maior parte, já para o item acessibilidade deixa a desejar, observando que a disposição dos blocos são confusas, não existe passarelas com cobertura adequada para facilitar o deslocamento e que o trajeto torna-se quase que impossível para um portador de necessidade especial, que os blocos mais novos possuem elevadores mais impossibilitados de uso e que as escadas não permitem o acesso de cadeirantes e pessoas que tenham dificuldade de mobilidade, o estacionamento precisa de mais organização e iluminação.

A biblioteca tem sua importância e, apesar de ser muito pequena e não disponibilizar um grande acervo, tem oferecido publicações que ajudam muito nos estudos.

A maior reivindicação é que o campus deveria dispor de um auditório composto de equipamentos necessário para acomodar participantes de grandes eventos da universidade inclusive as formaturas, e proporcionar também um ambiente de interação social e lazer além de dispor de espaço para pratica de esportes. Todos estes itens avaliados contribuem para a necessidade de revisão dos projetos de engenharia e do uso adequado dos espaços disponíveis.

O estudo aponta a necessidade de elaboração estratégias pedagógicas, e mais ação para o NDE - Núcleo Docente Estruturante.

\section{REFERÊNCIAS}

CHICKERING, A. W. e GAMSON, Z. F. Applying the serven principles for good practice in undergraduate education. São Francisco: Jossey Brass, 1991. New Directions for Teaching and Learning, $n^{\circ} 4$ DEMO, Pedro. Desafios modernos da educação. Petrópolis: Vozes, 1998 


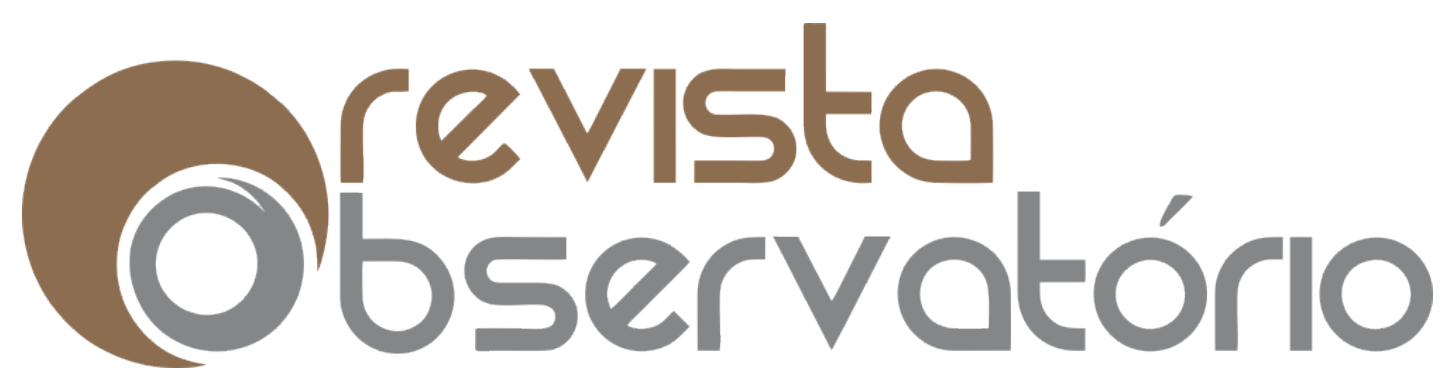

ISSN n² 2447-4266

Vol. 5, n. 5, Agosto. 2019

DOI: http://dx.doi.org/10.20873/uft.2447-4266.2019v5n5p426

DENCKER, Ada de Freitas Maneti. Pesquisa e interdisciplinaridade no ensino superior: uma experiência no curso de turismo. São Paulo: Aleph, 2002.

FONTENOT, G.; HENKE, L.; CARSON, K. Take action on customer satisfaction. Quality Progress, v.38, n. 7, p. 40-47, 2005.

FREIRE, P. Educação como prática da liberdade. 19 ed. Rio de Janeiro: Paz e Terra, 1989.

KOTLER. Philip; ARMSTRONG, Gary. Principios de Marketing. 9 ed. São Paulo: Prentice Hall,2003.

KOTLER, P.; KELLER, K. L. Administração de marketing. 12. ed. São Paulo: Pearson Prentice Hall, 1998.

LAS CASAS, A. L. Excelência em atendimento ao cliente: atendimento e serviço ao cliente como fator estratégico e diferencial competitivo. São Paulo: M. Books, 2012.

Administração de marketing: conceitos, planejamento e aplicações à realidade brasileira. 1. ed. São Paulo: Atlas, 2010.

LEMKE, Ana Paula. Solução computacional para um sistema de avaliação da qualidade dos serviços em IES, baseado nos parâmetros do pqsp. 2005. $94 \mathrm{f}$. Monografia (Bacharelado em Ciência da Computação) - Programa de Bacharelado em Ciência da Computação do Instituto de Física e Matemática da Universidade Federal de Pelotas, Pelotas, 2005. Disponível em: < http://www.ufpel.edu.br/prg/sisbi/bibct/acervo/info/2005/mono ana paula lem ke.pdf>

MALHOTRA, N. Pesquisa de marketing. 3.ed. Porto Alegre: Bookman, 2001.

MELO A.; URBANETZ, S. Fundamentos de Didática. Curitiba: Ibpex, 2008.

MOREIRA. Daniel. A. Didática do Ensino Superior Técnicas e Tendências. São Paulo. Ed. Pioneira, 2000.

NEVES, Adriane Bayerl; RAMOS, Cleber Fagundes. A imagem das instituições de ensino superior e qualidade do ensino de graduação: a percepção dos acadêmicos do curso de administração. In: ENCONTRO NACIONAL DOS CURSOS DE GRADUAÇÃO EM ADMINISTRAÇÃO, 12, São Paulo, 2001. São Paulo: ENANGRAD, 2001.

PILLI, Luis. Modelagem da importância dos atributos de produtos e serviços em estudos desatisfação. In: CONGRESSO BRASILEIRO DE PESQUISA, 1., 2004, São Paulo. Anais.São Paulo: [S.l.], 2004. 


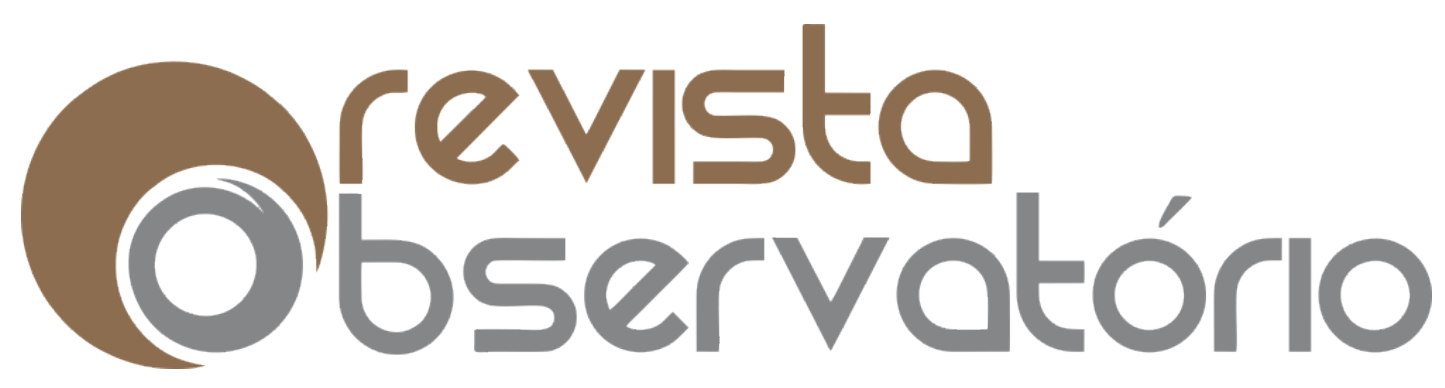

ISSN n² 2447-4266

Vol. 5, n. 5, Agosto. 2019

DOI: http://dx.doi.org/10.20873/uft.2447-4266.2019v5n5p426

Portal Education College. Disponível em: http://pt.educationcollege.info/continuing-education/other-continuing education/1009070146.html Acesso em 28/05/2016.

Portal Sociedade de Psicodrama de São Paulo. Disponível em: http://www.sopsp.org.br/index.php/a-importancia-da-relacao-professor-xaluno.Acesso em 28/05/2016.

Portal Palácio do Planalto Presidência da Republica do Brasil disponível em: www.planalto.gov.br/ccivil 03/ ato2004-2006/2004/lei/l10.861.htm acesso em: 26/05/2016.

$\mathrm{ROESCH}, \mathrm{S}$. M. A. Projetos de estágio e de pesquisa em administração: guia para estágios, trabalhos de conclusão, dissertações e estudos de caso. 2.ed. São Paulo: Atlas, 1999.

ROLIM, Rafael Campos, et al. Satisfação com o curso de graduação: um estudo junto aos estudantes de Administração da Universidade Federal de Lavras. In: ENCONTRO DA ANPAD, XXXI, Rio de Janeiro, 2007. Rio de Janeiro: EnANPAD, 2007.

UNIVERSIDADE FEDERAL DO AMAZONAS. Comissão Permanente de Avaliação. Retrospectiva da Avaliação da UFAM. Disponível em: http://www.cpa.ufam.edu.br/projeto-de-avaliacao/12-retrospectiva-daavaliacao-da-ufam.html . Acesso em: 21 mar. 2016.

WALTER, S. A.; TONTINI, G.; DOMINGUES, M. J. Identificando Oportunidades de Melhoria em um Curso Superior. In: ENCONTRO ANUAL DA ANPAD, 29, 2005,Salvador. Anais ... Brasília: ANPAD, 2005. 